${ }^{\star \star}$ This is a PsyArXiv Preprint version of the paper forthcoming in the Journal of Experimental Psychology: General ${ }^{\star *}$

An ideological asymmetry in the diffusion of moralized content on social media among political elites

William J. Brady ${ }^{1}$, Julian A. Wills², Dominic Burkart ${ }^{3}$, John T. Jost ${ }^{2,4}$ \& Jay J. Van Bavel $^{2,5}$

${ }^{1}$ Yale University, Department of Psychology

${ }^{2}$ New York University, Department of Psychology

${ }^{3}$ Princeton University, Department of Psychology

${ }^{4}$ New York University, Department of Politics and Center for Data Science

${ }^{5}$ New York University, Center for Neural Science

Word Count: 6438

Author Note

Correspondence concerning this article should be addressed to Jay Van Bavel, Department of Psychology, New York University. Contact: jay.vanbavel@nyu.edu. 
Author Contributions: W.J.B., J.A.W., J.T.J. and J.J.V.B. designed research; W.J.B., J.A.W., and D.B. performed research; W.J.B., J.A.W., J.T.J., and J.J.V.B. planned analyses; W.J.B. analyzed data; and W.J.B. wrote the paper and all authors contributed to revisions.

Acknowledgments: We thank Jino Kwon, Miaohan Wang, and Stephanie Leung for assistance with variable coding. We are also grateful to members of the NYU Social Perception and Evaluation Lab (@vanbavellab), the Brown Social and Affective Neuroscience Lab, and the Yale Crockett Lab for their comments and suggestions. This research was presented by W.J.B. at the Princeton Neuroscience and Social Decision Making meeting, the Boston Area Moral Cognition Group (BAM) meeting, and the 2018 Society for Personality and Social Psychology (SPSP) Annual Convention.

Grants: This research was supported by the National Science Foundation (Awards \#SES-1349089, SES-1248077, and SES-1248077-001) as well as the Global Institute for Advanced Study (GIAS) and Research Investment Fund (RIF) at New York University. 


\begin{abstract}
Online social networks constitute a major platform for the exchange of moral and political ideas, and political elites increasingly rely on social media platforms to communicate directly with the public. However, little is known about the processes that render some political elites more influential than others when it comes to online communication. Here, we gauge influence of political elites on social media by examining how message factors (characteristics of the communication) interact with source factors (characteristics of elites) to impact the diffusion of elites' messages through Twitter. We analyzed messages $(N=286,255)$ sent from federal politicians (Presidential candidates, Senate, House of Representatives) in the year leading up to the 2016 U.S. presidential election - a period in which Democrats and Republicans sought to maximize their influence over potential voters. Across all types of elites, we found a 'moral contagion' effect: elites' use of moral-emotional language was robustly associated with increases in message diffusion. We also discovered an ideological asymmetry: conservative elites gained greater diffusion when using moral-emotional language compared to liberal elites, even when accounting for extremity of ideology and other source cues. Specific moral emotion expressions related to moral outragenamely, moral anger and disgust—were particularly impactful for elites across the political spectrum, whereas moral emotion expression related to religion and patriotism were more impactful for conservative elites. These findings help inform the scientific understanding of political propaganda in the digital age, and also the potential antecedents of political polarization that is rapidly growing in American politics.
\end{abstract}

Keywords: morality, emotion, politics, social networks, social media 
An ideological asymmetry in the diffusion of moralized content on social media among political elites

For over 2 billion users of Twitter and Facebook, online social networks constitute a major platform for the exchange of moral and political ideas. Twitter now plays a major role in a wide range of political events, from elections to revolutions, and this influence appears to be growing. Political elites, such as President Donald Trump, increasingly rely upon social media platforms to communicate directly with the public. Although Hillary Clinton's campaign spent $\$ 500$ million more than Trump's campaign on advertising during the 2016 race (Allison, Rojanasakul, Harris, \& Sam, 2016), Trump credited social media with allowing him to overcome this disparity (Stahl, 2016). Unfortunately, social media also provides certain political actors with the capacities to engage in "cyberwarfare" and "sow conflict and discontent" in society (Timberg, Shaban, \& Dwoskin, 2017). This paper examines the role of moral-emotional expression and political ideology in the communications among political elites on social media.

There is reason to believe that elected and non-elected political elites can use social media to shape the moral and political attitudes of the public. Many political elites cultivate very large numbers of followers on social media, are especially influential in their groups (Hogg, 2010), have the highest capacity to spread ideas (Rogers, 2010), and are relatively extreme in terms of ideology and partisan identification (McCarty, Poole, \& Rosenthal, 2016). Thus, behavioral research is needed to illuminate the processes that render some political elites more influential than others when it comes to online communication. In fact, studying these individuals may provide the most powerful insights about why political information spreads online and the consequences it might 
have on real political behavior. Yet, little is known about the efficacy of various types of appeals to the massive audience on social media (see Jost et al., 2018).

Here, we gauge the influence of political elites in online social networks by examining how source factors (characteristics of elites) interact with message factors (characteristics of the communication) to impact the diffusion of elites' messages though online social networks (see McGuire, 1985; Petty \& Cacioppo, 1986). Information diffusion, which refers to the spread of information through direct and indirect ties that occurs through social sharing, is a major indicator of online social influence (e.g., Bakshy, Rosenn, Marlow, \& Adamic, 2012; Barberá, Jost, Nagler, Tucker, \& Bonneau, 2015). Compared to traditional advertising strategies, social media networks provide cost-effective means of reaching large numbers of people. Users often share messages on social media that represent beliefs, opinions, and values they endorse, as well as authors they trust (Metaxas et al., 2015). Thus, the frequency with which a political candidate or party is mentioned on Twitter is correlated with offline election outcomes (O’Connor, Balasubramanyan, Routledge, \& Smith, 2010; Tumasjan, Sprenger, Sandner, \& Welpe, 2011) and discussions of political protests predict subsequent offline behavior (Mooijman, Hoover, Lin, Ji, \& Dehghani, 2018). For all of these reasons, information diffusion through social sharing reflects the potential for political power: the extent to which elite opinions are actually reaching large audiences and broad constituencies.

A number of message factors contribute to the diffusion of moral and political messages in online social networks. When it comes to news articles, emotional content (Berger \& Milkman, 2012; Stieglitz \& Dang-Xuan, 2013) and moralistic language 
(Valenzuela, Piña, \& Ramírez, 2017) both predict increased rates of information diffusion. Political messages that contain both moral and emotional content are especially contagious - an effect we have termed 'moral contagion' (Brady, Wills, Jost, Tucker, \& Van Bavel, 2017). In the context of online social networks, moral contagion refers specifically to the diffusion of moralized content resulting from a process whereby moral and emotional expressions serve as information that influences people's evaluations and can shape their behavior (e.g., decisions to share content). For instance, social movements that are promoted in terms of moral and emotional content are more likely to be shared virally, presumably because this type of promotion makes people more likely to evaluate support for the movement as a moral imperative (Van Der Linden, 2017). Although these findings suggest that including moral and emotional expression in communications may help political elites to reach very large audiences, this idea has yet to be tested in a sample of political elites using social media platforms.

An important theoretical assumption of social psychology is that characteristics of the communication source (i.e., who is sending the message) often interact with the framing or content of the message (Chaiken, 1980; McGarty, Haslam, Hutchinson, \& Turner, 1994; McGuire, 1985; Petty \& Cacioppo, 1986). One source cue that is expected to interact with message content to affect diffusion is political ideology (Jost, van der Linden, Panagopoulos, \& Hardin, 2018). For instance, the diffusion of moralemotional language was greater within politically conservative (vs. liberal) online networks for the contentious political topic of climate change (Brady et al., 2017). This is consistent with research finding that conservatives are more sensitive than liberals to high-arousal emotions such as anger, contempt, anxiety, and threat, and more 
moralistic when it comes to social issues (Hibbing, Smith, \& Alford, 2014; Jost, 2017; Jost, Glaser, Kruglanski, \& Sulloway, 2003; Tomkins, 1995). In addition, there may be gender asymmetries in the effectiveness of certain types of message content. It is possible that citizens are more influenced by moral-emotional language when it is wielded by male rather than female politicians insofar as females are often evaluated negatively when they express high-arousal emotions (Brescoll \& Uhlmann, 2008; Lewis, 2000) —even when the emotions are gender-normative (Hutson-Comeaux \& Kelly, 2002; Thomas, 2016).

To explore potential interactions between source and message factors, we considered the roles of political ideology and gender, as well as the specific contents in social media messages sent by elected officials. Specifically, we analyzed a large sample of Twitter messages (Total $N=286,255$ ) sent by U.S. politicians in the year leading up to the 2016 presidential election—a period in which Democrats and Republicans sought to maximize their influence over potential voters.

Our sample of elite social media users included the two major presidential candidates as well as every member of the U.S. Senate and House of Representatives with a Twitter account during this period. This sample enabled us to investigate the extent to which processes of moral contagion are moderated by message source. In other words, do some politicians—such as conservatives or male politicians—benefit more than others (liberals and female politicians) when it comes to the use of moralemotional language in their online communications? These are important questions of a theoretical and practical nature about the elite usage of social media in democratic society. Not only would the answers to these questions illuminate the phenomenon of 
propaganda in the digital age, but it might also help to better understand some of the elements of affective polarization in American politics (McCarty et al., 2016).

\section{Current Research}

We describe the results of three large-scale studies of elite communication that directly investigated these questions about moral contagion among political elites and potential moderators of the effect, which has thus far been explored only in the context of social media usage by ordinary citizens (Brady et al., 2017). We analyzed Twitter messages sent by U.S. politicians in the year leading up to the 2016 presidential election (see Methods). Specifically, we collected tweets sent from the official accounts of Donald Trump and Hillary Clinton (Study 1) as well as all members of the Senate (Study 2) and all of U.S. Congress including the Senate and House of Representatives (Study 3). To gauge the extent to which social media messages contained moral and emotional language, we analyzed textual variation in the contents of messages. We used a text-mining technique that searches for keywords in messages based on previously validated dictionaries for measuring morality, emotion, and moral emotion (Brady et al., 2017; see Method below). Diffusion was indexed as the number of retweets each message received, because retweet counts provide a high-quality measure of information diffusion on Twitter (Barberá et al., 2015; Stieglitz \& Dang-Xuan, 2011).

\section{Study 1}

In Study $1(N=9,505)$ we investigated the use of moral and emotional language by Donald Trump and Hillary Clinton and its dissemination to determine whether (1) presidential candidates exhibit a moral contagion effect, and (2) variation in source cues 
such as ideology and gender moderate the effect. We also explored whether positive vs. negative moral emotion (valence analysis), or specific expressions of moral emotions (e.g. moral anger vs. moral disgust) had differential effects on diffusion for Trump and Clinton.

\section{Method}

Data collection. All research was conducted in accordance with the New York University (NYU) University Committee on Activities Involve Human Subjects (IRB no. 12-9058). Data collection was ruled "exempt" due to our use of public tweets only. A public tweet is a message that the user consents to be publicly available rather than only to a collection of approved followers. All data were collected by connecting to Twitter's API with the userTimeline function via Python's TweePy package. Data were collected in October, 2016 with the goal of collecting every tweet from Clinton and Trump dating back to November $8^{\text {th }}, 2015$ to represent 12 months leading up to the 2016 U.S. Presidential Election. Due to limitations from the Twitter API, which allows collection of $\sim 3000$ of a user's most recent messages, our target time range of 12 months prior to the 2016 election was only met by using the API in combination with webpage-scraping since Trump and Clinton tweeted more 3000 times in one year. All metadata for each tweet including retweet count, presence of media or URL, and follower number for each account were pulled directly from the API at the time of data collection. Thus, the retweet counts and follower number attached to each elite account were as of October 2016. We removed messages that elites had retweeted, and thus 
our final data sets consisted only of original messages composed by the elites' accounts. All data and analysis scripts are available at https://osf.io/reqx9/.

Measuring moral and emotional language. To measure morality and emotion, we searched tweets for the presence of keywords based on previously validated dictionaries for measuring morality and emotion, and formed 3 categories of distinctly moral, distinctly emotional, and moral-emotional words. Moral words were defined as those that appeared only in the moral dictionary (e.g., 'justice', 'holy', 'pure'); emotional words were those that appeared only in the emotion dictionary (e.g., 'sad', 'enjoy', 'annoyed'); and moral-emotional words were those that appeared in both (e.g., 'hate', 'murder', 'shame'). These theoretically-derived categories were based on previously validated dictionaries shown to have high discriminant validity in multiple pilot studies (for instance, participants rated moral-emotoinal words as more moral than distinctly emotoinal words and more emotional than distinctly moral words with a mean effect size of $d=2.23$; see Brady et al., 2017). Using this method, each tweet was assigned a count representing how many times each category of words appeared in the tweet.

Measuring positive vs. negative moral emotion. In order to measure positive and negative valence, we assessed each distinctly emotional and moral-emotional word's valence assignment based on the previously-validated LIWC dictionary (Tausczik \& Pennebaker, 2010).

Measuring specific expressions of moral emotion. In order to measure specific emotion expressions associated with moral-emotional words, we used the $R$ 'tidytext' package (Silge \& Robinson, 2016) which allowed us to tokenize each tweet and then classify each token as representing one or many discrete emotions (overlap in 
classification was allowed; e.g., "abused" is labeled as both disgust-related and angerrelated) based on the NRC sentiment analysis lexicon (Mohammad, Kiritchenko, \& Zhu, 2013). Words that were classified by our dictionary method as moral-emotional and also as a related to a specific emotion were counted as an instance of a discrete moral emotion.

Measuring diffusion. Diffusion was defined as retweet count per tweet, and retweet count was taken from meta data available from the Twitter API.

\section{Results}

We regressed the retweet count for each message on the count of distinctly moral, distinctly emotional, and moral-emotional words present in each message. For all studies, we log-transformed retweet count to form a normal distribution appropriate to perform OLS regression. We choose this method rather than using traditional count models (e.g., negative binomial) because political elites have an abnormally high number of retweets per tweet. Thus, the number of 0 occurrences is extremely rare (for instance, the minimum retweet count in President Trump's sample was 370, and Clinton's was 42), and model testing revealed that log-transformed OLS regression achieved better model fit than negative binomial regression models. The 10 moral and moral-emotional words that were associated with the two candidates' most viral tweets are shown in Fig. 1.

For Trump, we observed that messages using moral language were associated with a significant increase in retweet count, $\exp (b)=1.12, p<.001,95 \% \mathrm{Cl}=[1.08$, 1.17]. This effect translates to a predicted $12 \%$ increase in retweet count for each 
distinctly moral word included in a message. Although the use of distinctly emotional language actually associated with a slight reduction in retweet count, $\exp (b)=0.97, p=$ $.028,95 \% \mathrm{Cl}=[0.95,1.00]$, the use of moral-emotional language was associated with the largest significant increase, $\exp (b)=1.25, p<.001,95 \% \mathrm{Cl}=[1.18,1.32]$. This effect translates to a $25 \%$ increase in retweet count for each moral-emotional word added to the tweet. Thus, we see that Trump clearly benefitted from the moral contagion effect (see SI Appendix, Tables S1-S2 for full model details; all data and analysis scripts are available at https://osf.io/reqx9/).

We also examined Hillary Clinton's messages during the same period and observed that her use of distinctly emotional language was significantly associated with increased diffusion, $\exp (b)=1.05, p<.001,95 \% \mathrm{Cl}=[1.02,1.08]$. However, neither her use of distinctly moral language, $\exp (b)=1.01, p=.625,95 \% \mathrm{Cl}=[0.98,1.04]$, nor moral-emotional language, $\exp (b)=1.02, p=.490,95 \% \mathrm{Cl}=[0.97,1.07])$ predicted diffusion. Unlike Trump, Clinton failed to benefit from moral contagion (see SI Appendix, Tables S1-S2 for full model details).

When we combined the Trump and Clinton corpuses and used effects-coding to signify the source of the message (using Clinton as the reference category), we observed significant interactions between the effect of moral language and source, $\exp (b)=1.11, p<.001,95 \% \mathrm{Cl}=[1.06,1.17]$ and the effect of moral-emotional language and source, $\exp (b)=1.23, p=<.001,95 \% \mathrm{Cl}=[1.14,1.32]$, see Fig. 2 . Trump's use of moral and moral-emotional language resulted in significantly more diffusion in comparison with Clinton's, despite the fact that Clinton used more moral language and moral-emotional language than Trump on average (see Table 1). 

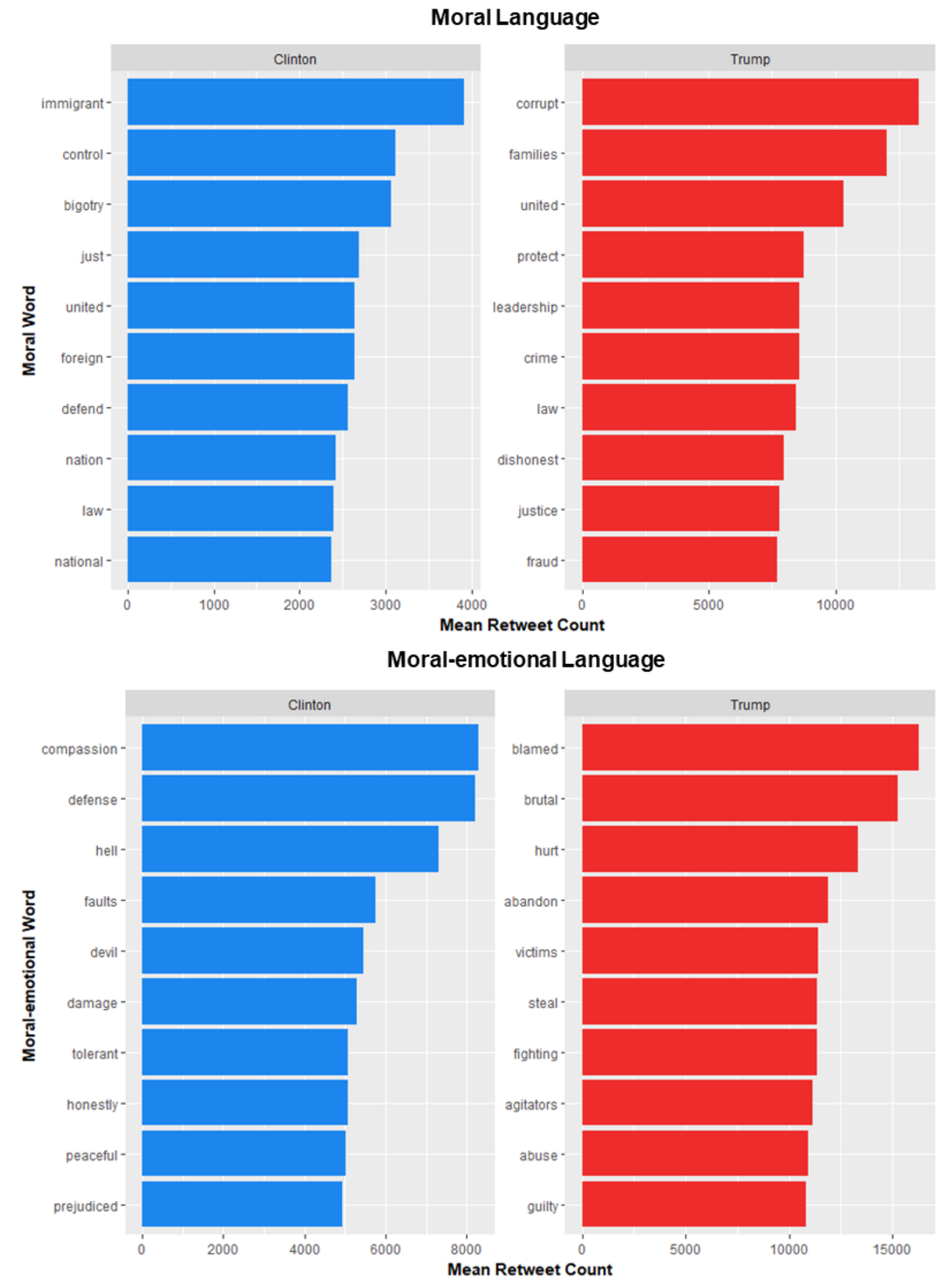

Figure 1. List of moral and moral-emotional words included in Donald Trump's and Hillary Clinton's most viral tweets leading up to the 2016 U.S. Presidential election, in order of mean retweet count. Words that were not used at least 10 times by the candidate are omitted. 
To further explore the asymmetry between Trump and Clinton, we examined the effects of word valence and discrete moral emotions (see Methods). Trump's use of positive moral-emotional language, $\exp (b)=1.16, p=<.001,95 \% \mathrm{Cl}=[1.03,1.31]$, and negative moral-emotional language, $\exp (b)=1.24, p=<.001,95 \% \mathrm{Cl}=[1.08,1.43]$, resulted in significantly more diffusion, in comparison with Clinton. Therefore, the asymmetry was not attributable to a difference in terms of the valence of moral emotions expressed (see SI Appendix, Table S3 for model details). We did observe, however, that for Trump the moral contagion effect was driven largely by the expression of moral anger, whereas for Clinton discrete moral emotions were not associated with increased retweet counts (see SI Appendix, Section 1).

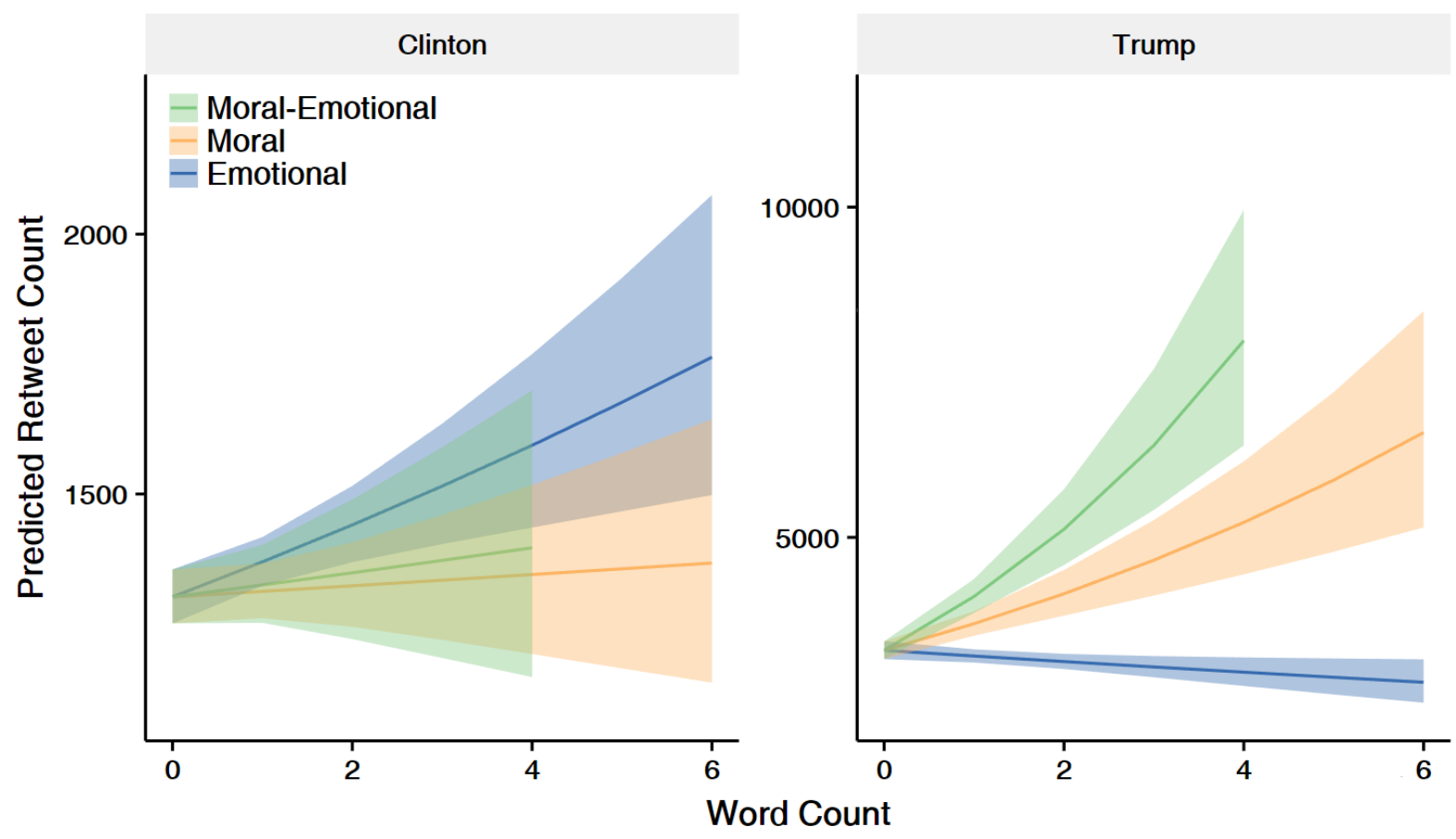

Figure 2. Donald Trump's use of moral and moral-emotional language was significantly associated with increased retweet rates, but this was not the case for Hillary Clinton. The graphic depicts the association between distinctly emotional (blue), distinctly moral (orange) and moral-emotional (green) language with retweet counts. Error bands represent 95\% confidence intervals. 


\begin{tabular}{lcclcc}
\hline \hline & \multicolumn{2}{c}{ Liberal } & & \multicolumn{2}{c}{ Conservative } \\
\cline { 2 - 3 } \cline { 5 - 6 } & Clinton & Congress & & Trump & Congress \\
\hline Moral & $0.54(0.81)$ & $0.50(0.76)$ & & $0.34(0.62)$ & $0.38(0.65)$ \\
Emotional & $0.75(0.87)$ & $0.90(0.96)$ & & $1.20(1.12)$ & $0.84(0.93)$ \\
Moral-emotional & $0.24(0.53)$ & $0.26(0.54)$ & & $0.19(0.46)$ & $0.25(0.53)$ \\
\hline \hline
\end{tabular}

Table 1. Descriptive statistics for moral, emotional, and moral-emotional language used by political candidates and members of Congress. Means represent the number of words from each language category used on average, per message.

\section{Study 2}

Study 1 provided evidence that the source of the message affects the dissemination of moral-emotional language used by presidential candidates. However, because Trump and Clinton differ on countless dimensions, it is impossible to determine whether the asymmetry was due to differences in political ideology, gender, or some other variable. Although Trump and Clinton carry some of the most potential for social media influence, further evidence is required to determine how generalizable potential source effects are to other political elites. Study 2 was designed to investigate with more precision the extent to which the specific source cues of political ideology and gender contribute independently to the moral contagion effect, as well as include a much larger sample of political elites.

\section{Method}

Data collection. Using the same methods as Study 1, we collected Twitter messages sent by all 100 U.S. Senators in the year leading up to the 2016 U.S. Presidential election $(N=99,750)$. To statistically adjust for confounding variables that can affect message diffusion, we pulled metadata for Senators and their messages including follower number and the presence of URL and/or media in each message. Metadata were pulled directly from the API at the time of data collection. Thus, the 
retweet counts and follower number attached to each elite account were as of October, 2016. We removed messages that elites had retweeted, and thus our final data sets consisted only of original messages composed by the elites' accounts.

Measuring morality and emotion, valence, and specific emotion expressions. We used the same text-mining techniques as in Study 1.

Measuring political ideology. To measure the political party membership of each elite, we pulled an estimate of their ideology based on voting recordings using the freely available DW-NOMINATE database (Poole \& Rosenthal, 1985). This database assigns congress members a continuous ideology value based on their voting records where negative values indicate a liberal-learning voting pattern and positive values indicate a conservative-learning voting pattern. We also formed a measure of extremity of ideology and it was defined as the scaled absolute value of the DW-NOMINATE score (see Results below). We scaled the extremity variable so that the range of ideology was the same for both conservatives and liberals (see SI Appendix, Section 2).

Measuring gender. Gender was measured as an effects-coded binary (male/female) variable based on the sex of the Senator, where males were defined as the reference group.

\section{Results}

We analyzed messages nested within elites in a multi-level model and regressed retweet count on the use of distinctly moral, distinctly emotional, and moral-emotional 
language, as well as covariates known to affect retweet rate (URL, media, follower number). Our multi-level model accounted for non-independence of data using Generalized Estimating Equations (GEE) with robust standard error estimation (Hardin, 2005), and an exchangeable correlation structure.

The analysis revealed that distinctly moral language, $\exp (b)=1.13, p<.001$, $95 \% \mathrm{Cl}=[1.09,1.18]$. and moral-emotional language, $\exp (b)=1.13, p<.001,95 \% \mathrm{Cl}=$ $[1.08,1.18]$, were associated with significant increases in message diffusion, whereas distinctly emotional language was not, $\exp (b)=0.97, p=.268,95 \% \mathrm{Cl}=[0.92,1.02]$; see SI Appendix, Table S6 for full model details). This effect translates to a $13 \%$ increase in retweet count for each moral-emotional word added (and the same for each moral word). Thus, we confirm that U.S. Senators benefitted from a moral contagion effect in the year leading up to the presidential election.

To investigate possible asymmetries in terms of political ideology, we regressed retweet count on the interaction of each language category and the continuous ideology estimation of each Senator. We observed no evidence of ideological differences in the effect of distinctly moral language, $\exp (b)=0.99, p=.811,95 \% \mathrm{Cl}=[0.89,1.10])$, but the diffusion of moral-emotional language was indeed greater among more conservative Senators, $\exp (b)=1.12, p=.047,95 \% \mathrm{Cl}=[1.00,1.25]$. Thus, we found preliminary evidence for ideological asymmetry in the moral contagion effect (see Fig. 3). There was also marginal evidence of an ideological difference in the effect of distinctly emotional language, $\exp (b)=1.13, p=.068,95 \% \mathrm{Cl}=[0.99,1.29]$; see SI Appendix, Table S7 for full model details). Adjusting for the extremity of ideology for each Senator 
also revealed that more extreme Senators exhibited a greater moral contagion effect (see SI Appendix, Section 2 for more details).

It is worth noting that 2 conservative senators (Jeff Sessions and Thom Tillis) as well as 1 liberal senator (Cory Booker) were greater than 3 standard deviation outliers in their respective moral contagion estimates (see Figure 3). When these outliers were removed, the above results remained consistent and in fact yielded less noisy and larger estimates: the conservative advantage in the moral contagion effect was larger, $\exp (b)=1.17, p<.001,95 \% \mathrm{Cl}=[1.08,1.26]$. This is likely due to the fact that Cory Booker showed a very large moral contagion effect that was less typical of liberal Senators, but also had the largest number of observations (see SI Appendix, Table S8).

To examine whether gender also explained variance in the moral contagion effect, we additionally entered the sex of the Senators in our model (20 Senators were female, 80 males were specified as the reference group). We observed that when adjusting for the interaction of political ideology and each language category, there were no significant interactions of gender with respect to distinctly moral, $\exp (b)=0.94, p=$ $.101,95 \% \mathrm{Cl}=[0.88,1.01]$, distinctly emotional, $\exp (b)=1.07, p=.108,95 \% \mathrm{Cl}=$ $[0.99,1.16]$, nor moral-emotional language, $\exp (b)=0.93, p=.089,95 \% \mathrm{Cl}=[0.86$, 1.01]. However, in this model the interaction of ideology and moral-emotional language did not remain significant, $\exp (b)=1.10, p=.119,95 \% \mathrm{Cl}=[0.98,1.24]$; see SI Appendix, Table S9). This suggests that in the Senate data ideology and gender explained shared variance in the moral contagion effect. Thus, in this data set alone it is impossible to determine which variable plays more of an explanatory role in the moral contagion effect. However, again it is worth noting that when influential outliers were 
removed, the effect of ideology on the moral contagion effect did explain significant variance when adjusting for gender, $\exp (b)=1.16, p<.001,95 \% \mathrm{Cl}=[1.07,1.25]$ but the effect of gender on the moral contagion effect was still non-significant, $\exp (b)=$ 0.93, $p=.225,95 \% \mathrm{Cl}=[0.90,1.02]$; see SI Appendix, Table S10.

We also explored the role of emotional valence and discrete emotions: the difference between conservative and liberal Senators in moral contagion was driven primarily by positively-valenced moral-emotional language, $\exp (b)=1.14, p=.001,95 \%$ $\mathrm{Cl}=[1.04,1.25]$, rather than negatively-valenced moral-emotional language, $\exp (b)=$ $1.02, p=.812,95 \% \mathrm{Cl}=[0.85,1.23]$; see SI Appendix, Table S11). Our specific moral emotion analysis revealed that anger and disgust-related moral emotion drove moral contagion for both ideologies, but conservative Senators benefitted more than liberal Senators when they used moral-emotional expressions classified as "joy," which included references to religion and patriotism (e.g., "faith", "respect", "hero"; see SI Appendix, Section 1 for details). In sum, we found evidence of an ideological asymmetry in moral contagion; the messages containing moral-emotional language were disseminated more widely for conservative Senators than liberal Senators, although both sides of political generally exhibited the moral contagion effect. The moralemotional words that were associated with the most viral tweets for Conservative vs. Liberal candidates are shown in Fig. 4.

Taken together, the results of Study 1 and 2 provide preliminary evidence of an ideological symmetry in the moral contagion effect: conservatives elites showed a relatively greater effect of moral-emotional language compared to liberal elites, although both ideologies showed significant moral contagion effects. However, due to influential 
outliers and shared variance with gender, it is difficult to determine how reliable the effect may be. In order to solve this issue, in Study 3 we expanded our data collection to also include the House of Representatives, thus providing a much larger and more representative sample including all of Congress.

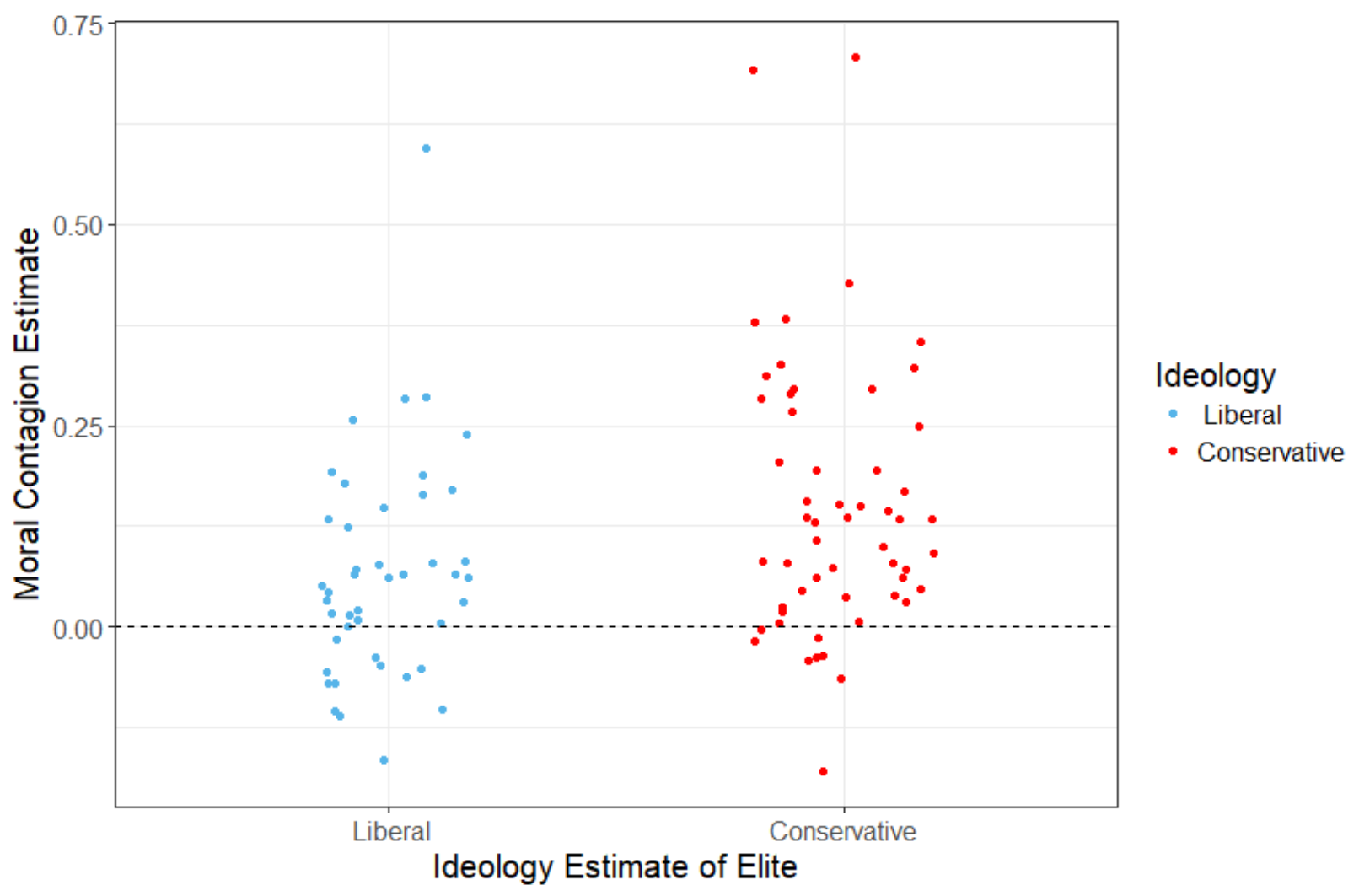

Figure 3. Moral contagion estimates (the effect of moral-emotional language on diffusion) plotted by senator and political party. Each dot represents the point-estimate of the moral contagion effect for an individual senator; positive values represent a positive moral contagion effect, negative values represent a negative moral contagion effect. Liberal senators are blue and conservative senators are red. 


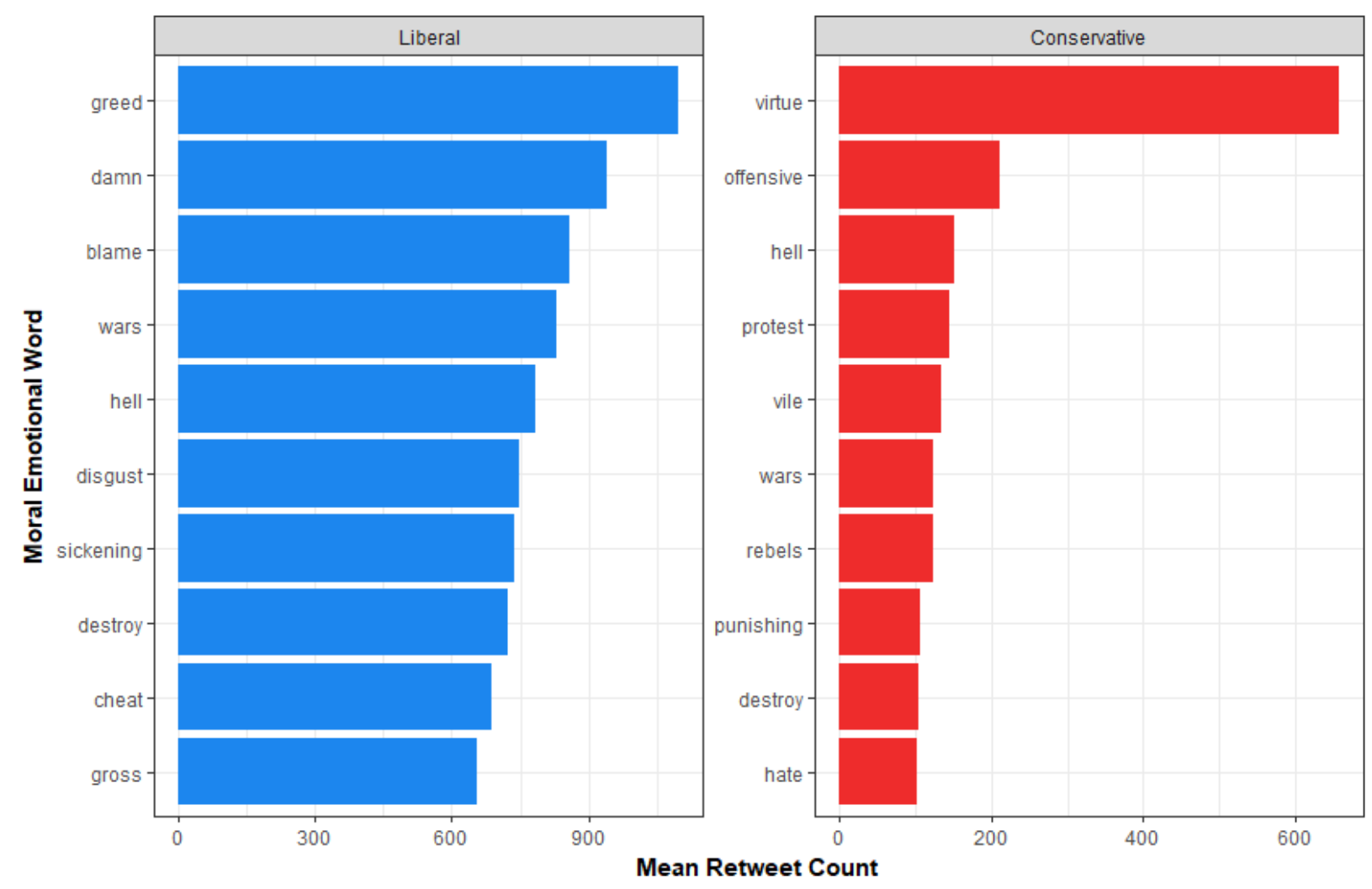

Figure 4. List of moral-emotional words associated with the Senate and House of Representatives' most viral tweets leading up to the 2016 U.S. Presidential election, in order of mean retweet count. Words that failed to appear at least 10 times for liberal and conservative congress members are excluded.

\section{Study 3}

In Study 3, we sought to test the reliability of the results of Study 2 in a larger and more representative sample including all of Congress by incorporating Senate members and House of Representative members. By doing so, we were also able to explore the effects of other automatically perceived social category cues (race and age; Brewer, 1988; Fiske \& Neuberg, 1990) that could impact diffusion including the age and race of Congress members.

\section{Method}

Data collection. We collected Twitter messages from 372 Representatives with available Twitter messages in the year leading up to the 2016 U.S. Presidential Election 
$(N=177,000)$ using the same methods as Study 2, and combined the Senate data from Study 2 to form one data set representing all of U.S. Congress $(N=276,750)$. As in Study 2 , to statistically adjust for confounding variables that can affect message diffusion, we pulled metadata for Congress members and their messages including follower number and the presence of media in each message (URL metadata was lost due to an error in our programming script for Representatives). All metadata were pulled directly from the API at the time of data collection. Thus, the retweet counts and follower number attached to each elite account were as of October, 2016. We removed messages that elites had retweeted, and thus our final data sets consisted only of original messages composed by the elites' accounts.

Measuring morality, emotion, valence and specific emotions. We used the same text-mining techniques as in Studies 1 and 2.

Measuring political ideology and gender. The same methods as Study 2 were used to measure ideology and gender.

Measuring age and race. Race was measured based on binary classification (white / non-white) based on the image of each Congress member from Wikipedia. Age was also determined based on the age reported on each Congress member's Wikipedia page.

\section{Results}

Among all Congress members, distinctly moral language, $\exp (b)=1.13, p<.001$, $95 \% \mathrm{Cl}=[1.11,1.14]$, and moral-emotional language, $\exp (b)=1.12, p<.001,95 \% \mathrm{Cl}=$ $[1.10,1.14]$, were both associated with greater diffusion, but distinctly emotional language was not, $\exp (b)=0.98, p=.143,95 \% \mathrm{Cl}=[0.96,1.01]$; see SI Appendix, 
Table S15 for model details). This effect translates to a $12 \%$ increase in retweet count for each moral-emotional word (and 13\% for each moral word). These results confirm that elected political elites did consistently benefit from moral contagion in the year before the national election.

We also investigated the ideological asymmetry effect in moral contagion in the case of messages sent by all Congress members. No ideological difference was observed with respect to the diffusion of distinctly moral language, $\exp (b)=1.00, p=$ $.860,95 \% \mathrm{Cl}=[0.96,1.05])$, but the diffusion of moral-emotional language was significantly greater for more conservative Representatives, $\exp (b)=1.07, p=.010$, $95 \% \mathrm{Cl}=[1.02,1.12]$, replicating the ideological asymmetry in moral contagion observed in Study 2 (see Figure 5) in a larger, more representative sample. In addition, the diffusion of distinctly emotional language was significantly greater for more conservative congress members, $\exp (b)=1.07, p=.030,95 \% \mathrm{Cl}=[1.01,1.14]$; see SI Appendix, Table S16 for model details. This finding is interesting in light of the fact the Clinton, a liberal elite, showed a greater effect of distinctly emotional language. The effects associated with Clinton may be unique in some regard due to her special status as a female presidential candidate at the time of the 2016 campaign.

The ideological asymmetry in the effect of moral-emotional language remained significant when adjusting for the effects of ideological extremity, although the effect of extremity was also significant (see SI Appendix, Section 2). The ideological asymmetry in the effect of moral-emotional language also remained significant in a model adjusting for the effects of gender, $\exp (b)=1.07, p=.015,95 \% \mathrm{Cl}=[1.01,1.13]$. When adjusting for ideology, there were no significant effects of gender on diffusion for any language 
categories, see SI Appendix, Table S17. Thus, ideology appeared to explain variance in the moral contagion effect over and above gender effects.

With our larger, more representative sample of Congress, we also examined source cues of race and age (Brewer, 1988; Fiske \& Neuberg, 1990) in a competing model with ideology and gender. This model revealed that the ideological asymmetry explained unique variance even when statistically adjusting for the effects of all other potential source cues we measured, $\exp (b)=1.07, p=.007,95 \% \mathrm{Cl}=[1.02,1.12]$. Although there was no effect of gender, there were independent effects of race and age on moral contagion: non-white congress members exhibited a relatively greater effect as well as younger congress members, see SI Appendix, Table S18.

In Studies 1-3, then, we observed that the moral contagion effect was stronger for conservative (vs. liberal) political elites. Study 3 in particular demonstrates, with all members of U.S. congress, that the ideological asymmetry explains unique variance over and above source gender, ideological extremity, race and age.

As in Study 2, we observed that the ideological asymmetry was driven more by positive moral-emotional language, $\exp (b)=1.10, p<.001,95 \% \mathrm{Cl}=[1.06,1.15]$ than negative moral-emotional language, $\exp (b)=0.98, P=.639,95 \% \mathrm{Cl}=[0.91,1.06]$; see SI Appendix, Table S19 for model details). We also replicated the discrete moral emotion finding from Study 2: moral-emotional language that was associated with "joy" (including religious and patriotic language) resulted in greater diffusion for conservative than liberal Congress members. Moral anger (but not disgust) was again associated with greater diffusion for both liberals and conservatives (see SI Appendix, Section 1 for details). In all three studies, exploratory analyses based on valence and discrete moral 
emotions suggested that the ideological asymmetry in moral contagion appears to be driven mainly by religious and patriotic language, and moral anger and (to a lesser extent) disgust language may be impactful across the political spectrum.

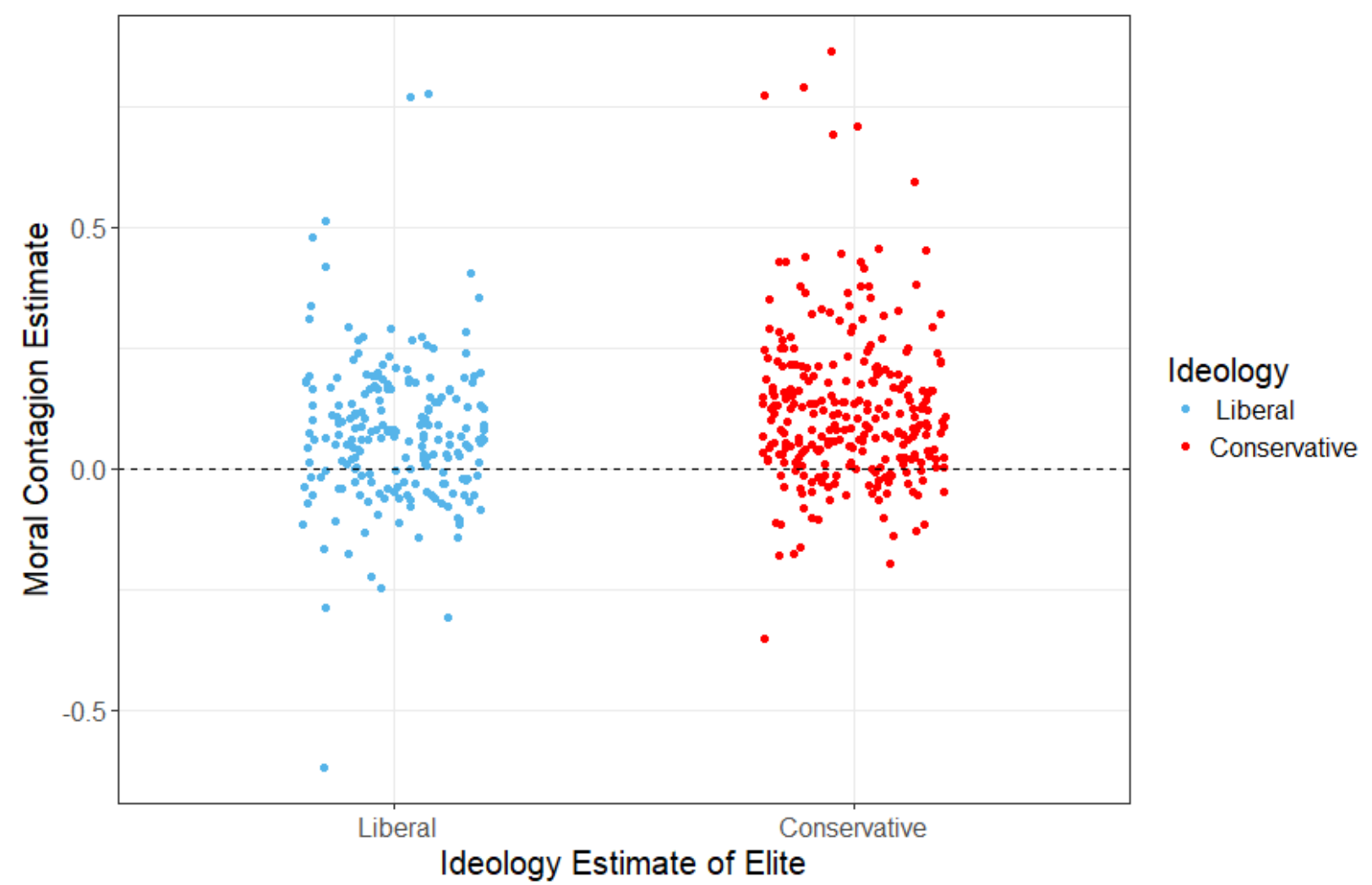

Figure 5. Visualization of moral contagion estimates by representative and political party. Each dot represents the point-estimate of the moral contagion effect; positive values represent a positive moral contagion effect, negative values represent a negative moral contagion effect. Liberal senators are blue and conservative senators are red.

\section{General Discussion}

For the two major Presidential candidates and Members of the U.S. Congress, messages that included the combination of morality and emotion were associated with increased diffusion through social networks. This pattern of results replicates the "moral contagion effect" found in a large-scale study of citizens (Brady et al., 2017) and suggests that the same patterns extend to political elites with massive followings. Taken 
together, these findings reveal that moral contagion is a robust phenomenon in regards to political discourse on social media and illuminate the ways in which political elites gain social influence and exposure.

This work extends research on the role of emotion in moral and political discourse (Haidt, 2001; Skitka, 2010), and attitude formation and change (Petty \& Cacioppo, 1986), to digital platforms and online social networks. It also suggests that emotional appeals lacking moral content may not always be sufficient to activate political engagement online (cf. Berger \& Milkman, 2012). As moral and political discourse increasingly floods social media environments designed to capture attention (Rose-Stockwell, 2017), the content that appeals to the moral values of political identities is especially popular, regardless of message veracity (Pereira \& Van Bavel, 2018), and may help explain why fake news spreads farther, faster and deeper than truth (Vosoughi, Roy, \& Aral, 2018). While our research demonstrates that moral and emotional content is associated with viral spreading within political networks, future research should investigate whether the particular design of social media platforms amplifies the attraction to moral and emotional expression (Crockett, 2017).

Our research sheds light on moderating variables that help us to understand when online appeals to morality and emotion may be more or less effective. While both liberal and conservative elites might increase message diffusion by drawing on moralemotional language, on average conservative elites produced larger moral contagion effects than liberal elites. It appears that Donald Trump benefitted from a social media advantage over Hillary Clinton in 2016 in part because of a conservative advantage when it comes to spreading provocative moral and emotional content. More broadly, 
insofar as social media influence can exert influence on political attitudes and behavior (Jost, Barberá, et al., 2018), our results suggest that moral and emotional content may be used strategically to draw online engagement and aid political campaigns. However, to fully understand how effective moral contagion is for political campaigns, further research is required to confirm the effects across multiple elections.

One practical limitation of these findings is that we were not able to track the extent to which the conservative advantage in moral contagion can be explained by bot activity during the election. For instance, some findings suggest that bots heavily favored Trump over Clinton through retweeting during the election campaign (Kollanyi, Howard, \& Woolley, 2016). However, it is important to note that estimates of bot activity relative to all of Twitter's political tweets are low, with estimates ranging from 1\% (O'Sullivan, 2018) to $18 \%$ (Bessi \& Ferrara, 2016) of all political tweets. In a recent (July, 2018) crackdown on bot accounts, Twitter deleted 100,000 accounts from President Trump's followers that appeared to be bots, but this represented only $0.002 \%$ of his total follower number (53.4 million; Dwoskin, 2018). Although the role of bots in online political campaigns are important to study, it is unlikely that bots could entirely explain our results due to the relatively low presence compared to human users. Furthermore, it is unclear why bots would selectively retweet political messages with moral-emotional content over other political messages on the exact same topic, unless they are more sophisticated than we are currently aware. In fact, research suggests that bots mostly tweeted candidate-supporting content during the 2016 election (Bessi \& Ferrara, 2016). It is nevertheless worth examining the extent to which bots either 
purposely or accidentally utilize moral contagion to increase online influence with their posting and retweeting behavior.

Exploratory analyses in Study 3 suggested that sources cues other than political ideology may contribute independently to variation in the moral contagion effect: in the U.S. Congress, tweets sent by non-white elites and younger elites exhibited stronger moral contagion effects. These findings point to the possible importance of social categorization (and stereotyping) processes when it comes to information diffusion in online social networks (Macrae \& Bodenhausen, 2000). Future work would do well to investigate this possibility in the context of moral-emotional language used by large and diverse groups of ordinary citizens.

In this research, we focused exclusively on characteristics of the source of social media messages, but future work would do well to consider "receiver effects," that is, the extent to which characteristics of online audiences moderate the moral contagion effect. Presumably, conservative elites gained online influence from the use of moralemotional language because like-minded followers were more likely to spread messages containing such language. However, because we focused on retweet counts and were not able to track the political ideology of all users who retweeted each message, this research cannot determine whether conservative audiences would also be more likely to spread moral-emotional content when it comes from a liberal source. In fact, our previous research suggests that moral-emotional messages are more likely to be shared within ideological bubbles (Brady et al., 2017).

It is also important to keep in mind that our studies focused on a very specific one-year time period (the year leading up to the 2016 U.S. Presidential election). Future 
research is needed to determine how robust these ideological asymmetries based on source cues are to contextual factors such as the historical period and political environment (see Van Bavel, Mende-Siedlecki, Brady, \& Reinero, 2016). For example, it may be that the ideological asymmetry in moral-emotional contagion is sensitive to which political party has Presidential power, such that the party out of Presidential power gains more from appeals to moral emotion that can help affirm their constituent's threatened political identity (Hogg, 2006). It is also conceivable that the ideological differences would get smaller after the Republicans swept the Federal elections in 2016 or that moral contagion effect would operate differently in other political systems that vary in terms of the degree of ideological polarization and the number of competing political parties. Our data also examined a specific type of elected elite: Presidential candidates, Senate and House members. Future research is required to determine how well these results generalize to other types of elites including non-elected political leaders who may have influence on public discourse as well (e.g., prominent figures in the media).

Our research extends the study of moral psychology and affective science in online social networks by investigating moral emotions at multiple levels of analysis (i.e., as a broad category, in terms of valence, and in terms of specific, discrete expressions of moral emotions). The current results suggested that appears to moral anger consistently increased message diffusion for Donald Trump and members of the U.S. Congress (but not for Hillary Clinton). That specific emotions may be more salient during political discourse is consistent with socio-functional accounts of emotion that stress the communicative function of emotion in guiding social interactions (Campos, 
Mumme, Kermoian, \& Campos, 1994; Keltner \& Haidt, 1999). Future research should map out how specific emotional expressions bolster moral claims (e.g., Rozin, Lowery, Imada, \& Haidt, 1999) in online social networks. For instance, anger increases opinion confirmation and decreases political information-seeking online (Valentino, Hutchings, Banks, \& Davis, 2008), whereas fear can increase political information-seeking (Huddy, Feldman, \& Cassese, 2007). Our research is among the first to measure specific expressions of moral emotion in online networks, although lexicon-based methods for measuring emotion come with some limitations such as insensitivity to word negations (Kern et al., 2016). Newer computational techniques such as machine-learning can be used to improve upon the shortcomings of lexicon-based approaches (Baharudin, Lee, \& Khan, 2010), but the ideal approach is to combine multiple methods of measuring and analyzing emotional expression insofar as emotions are multi-componential phenomena (e.g., valence, arousal; Russell \& Barrett, 1999).

In summary, we found robust evidence for the moral contagion effect among political elites, and that conservative elites were associated with a relatively larger moral contagion effect than liberal elites. Examining all U.S. Congress members revealed that this ideological asymmetry was robust to other possible source effects on moral contagion including gender, race and age of Congress members. Furthermore, the asymmetry appeared to be driven in large part by conservatives' use of positive moralemotional language related to patriotism and religion. On the other hand, expressions of moral anger and (to a lesser extent) disgust were associated with increased retweets for both conservatives and liberals, including a large effect of moral anger for Trump in the year leading up to his victory in the 2016 election. 


\section{References}

Allison, B., Rojanasakul, M., Harris, B., \& Sam, C. (2016). Tracking the 2016 Presidential Money Race. Retrieved January 30, 2018, from https://www.bloomberg.com/politics/graphics/2016-presidential-campaignfundraising/

Baharudin, B., Lee, L. H., \& Khan, K. (2010). A Review of Machine Learning Algorithms for Text-Documents Classification. Journal of Advances in Information Technology. Bakshy, E., Rosenn, I., Marlow, C., \& Adamic, L. (2012). The role of social networks in information diffusion. WWW 2012 - Session: Information Diffusion in Social Networks April 16-20, 2012, Lyon, France, 519-528.

Barberá, P., Jost, J. T., Nagler, J., Tucker, J. A., \& Bonneau, R. (2015). Tweeting From Left to Right: Is Online Political Communication More Than an Echo Chamber? Psychological Science, 26(10), 1531-1542.

Berger, J., \& Milkman, K. L. (2012). What makes online content viral? Journal of Marketing Research, 49(2), 192-205.

Bessi, A., \& Ferrara, E. (2016). Social bots distort the 2016 U.S. Presidential election online discussion. First Monday, 21(11).

Brady, W. J., Wills, J. A., Jost, J. T., Tucker, J. A., \& Van Bavel, J. J. (2017). Emotion shapes the diffusion of moralized content in social networks. Proceedings of the National Academy of Sciences, 114(28), 7313-7318.

Brescoll, V. L., \& Uhlmann, E. L. (2008). Can an angry woman get ahead? Status conferral, gender, and expression of emotion in the workplace: Research article. Psychological Science. 
Brewer, M. B. (1988). A dual process model of impression formation. In T. K. Srull \& R. S. Wyer (Eds.), Advances in Social Cognition (pp. 1-36). Hillsdale, NJ: Lawrence Erlbaum Associates.

Campos, J. J., Mumme, D. L., Kermoian, R., \& Campos, R. G. (1994). A functionalist perspective on the nature of emotion. Monographs of the Society for Research in Child Development.

Chaiken, S. (1980). Heuristic versus systematic information processing and the use of source versus message cues in persuasion. Journal of Personality and Social Psychology.

Crockett, M. J. (2017). Moral outrage in the digital age. Nature Human Behaviour, 1(11), 769-771.

Dwoskin, E. (2018). Trump, Obama and other high-profile Twitter users could see a 'significant drop' in followers. Here's why. Retrieved from https://www.washingtonpost.com/technology/2018/07/11/get-ready-your-twitterfollowers-are-about-drop/?noredirect=on\&utm_term=.eea94a6b9577

Fiske, S. T., \& Neuberg, S. L. (1990). A Continuum of Impression Formation, from Category-Based to Individuating Processes: Influences of Information and Motivation on Attention and Interpretation. Advances in Experimental Social Psychology.

Haidt, J. (2001). The emotional dog and its rational tail: a social intuitionist approach to moral judgment. Psychological Review, 108(4), 814-834.

Hardin, J. W. (2005). Generalized estimating equations (GEE). In B. Everitt \& D. Howell (Eds.). Hoboken, NJ: Wiley Online Library. 
Hibbing, J. R., Smith, K. B., \& Alford, J. R. (2014). Differences in negativity bias underlie variations in political ideology. Behavioral and Brain Sciences, 37(3), 297-307.

Hogg, M. A. (2006). Social Identity Theory. In Contemporary Social Psychological Theories (pp. 111-136).

Hogg, M. A. (2010). Influence and leadership. Handbook of Social Psychology. John Wiley \& Sons.

Huddy, L., Feldman, S., \& Cassese, E. (2007). On the distinct political effects of anxiety and anger. In W. R. Neuman, G. E. Marcus, M. Mackuen, \& N. Crigler (Eds.), The affect effect: Dynamics of emotion in political thinking and behavior (pp. 202-230). Chicago: University of Chicago Press.

Hutson-Comeaux, S. L., \& Kelly, J. R. (2002). Gender stereotypes of emotional reactions: How we judge an emotion as valid. Sex Roles.

Jost, J. T. (2017). Ideological Asymmetries and the Essence of Political Psychology. Political Psychology, 38(2), 167-208.

Jost, J. T., Barberá, P., Bonneau, R., Langer, M., Metzger, M., Nagler, J., ... Tucker, J. A. (2018). How Social Media Facilitates Political Protest: Information, Motivation, and Social Networks. Political Psychology, 39, 85-118.

Jost, J. T., Glaser, J., Kruglanski, A. W., \& Sulloway, F. J. (2003). Political conservatism as motivated social cognition. Psychological Bulletin.

Jost, J. T., van der Linden, S., Panagopoulos, C., \& Hardin, C. D. (2018). Ideological asymmetries in conformity, desire for shared reality, and the spread of misinformation. Current Opinion in Psychology.

Keltner, D., \& Haidt, J. (1999). Social functions of emotions at four levels of analysis. 
Cognition and Emotion, 13(5), 505-521.

Kern, M. L., Park, G., Eichstaedt, J. C., Schwartz, H. A., Sap, M., Smith, L. K., \& Ungar, L. H. (2016). Gaining insights from social media language: Methodologies and challenges. Psychological Methods.

Kollanyi, B., Howard, P. N., \& Woolley, S. C. (2016). Bots and Automation over Twitter during the First U.S. Election. Comprop Data Memo, 1, 1-4.

Lewis, K. M. (2000). When leaders display emotion: How followers respond to negative emotional expression of male and female leaders. Journal of Organizational Behavior.

Macrae, C. N., \& Bodenhausen, G. V. (2000). Social Cognition: Thinking Categorically about Others. Annual Review of Psychology, 51(1), 93-120.

McCarty, N., Poole, K., \& Rosenthal, H. (2016). Polarized America: The Dance of Ideology and Unequal Riches (2nd ed.). Cambridge: MIT Press.

Mcgarty, C., Haslam, S. A., Hutchinson, K. J., \& Turner, J. C. (1994). The effects of salient group memberships on persuasion. Small Group Research, 25(2), 267-293.

McGuire, W. J. (1985). Attitudes and Attitude Change. In G. Lindzey \& E. Aronson (Eds.), Handbook of Social Psychology, Volume II: Special fields and applications (3rd ed.). New York: Random House.

Metaxas, P. T., Mustafaraj, E., Wong, K., Zeng, L., Keefe, M. O., \& Finn, S. (2015). What do Retweets indicate? Results from User Survey and Meta-Review of Research. In Association for the Advancement of Artificial Intelligence (pp. 658661).

Mohammad, S. M., Kiritchenko, S., \& Zhu, X. (2013). NRC-Canada: Building the State- 
of-the-Art in Sentiment Analysis of Tweets.

Mooijman, M., Hoover, J., Lin, Y., Ji, H., \& Dehghani, M. (2018). Moralization in social networks and the emergence of violence during protests. Nature Human Behaviour, 2(6), 389-396.

O'Connor, B., Balasubramanyan, R., Routledge, B. R., \& Smith, N. a. (2010). From tweets to polls: Linking text sentiment to public opinion time series. From Tweets to Polls: Linking Text Sentiment to Public Opinion Time Series.

O'Sullivan, D. (2018). Russian bots retweeted Trump nearly 500,000 times in final weeks of 2016 campaign. Retrieved from https://money.cnn.com/2018/01/27/technology/business/russian-twitter-botselection-2016/

Petty, R. E., \& Cacioppo, J. T. (1986). The Elaboration Likelihood Model of Persuasion. Advances in Experimental Social Psychology.

Poole, K. T., \& Rosenthal, H. (1985). A spatial model for legislative roll call analysis. American Journal of Political Science, 357-384.

Rogers, E. M. (2010). Diffusion of innovations. New York, NY: Simon and Schuster. Rose-Stockwell, T. (2017). This Is How Your Fear and Outrage Are Being Sold for Profit. Retrieved January 2, 2018, from https://medium.com/the-mission/the-enemyin-our-feeds-e86511488de

Rozin, P., Lowery, L., Imada, S., \& Haidt, J. (1999). The CAD triad hypothesis: a mapping between three moral emotions (contempt, anger, disgust) and three moral codes (community, autonomy, divinity). Journal of Personality and Social Psychology, 76(4), 574-586. 
Russell, J. A., \& Barrett, L. F. (1999). Core affect, prototypical emotional episodes, and other things called emotion: Dissecting the elephant. Journal of Personality and Social Psychology.

Silge, J., \& Robinson, D. (2016). tidytext: Text Mining and Analysis Using Tidy Data Principles in R. JOSS, 1(3).

Skitka, L. J. (2010). The Psychology of Moral Conviction. Social and Personality Psychology Compass, 4, 267-281.

Stahl, L. (2016). President-elect Trump speaks to a divided country. Retrieved January 30, 2018, from https://www.cbsnews.com/news/60-minutes-donald-trump-familymelania-ivanka-lesley-stahl/

Stieglitz, S., \& Dang-Xuan, L. (2011). Political communication and influence through microblogging - An empirical analysis of sentiment in Twitter messages and retweet behavior. In Proceedings of the Annual Hawaii International Conference on System Sciences (pp. 3500-3509).

Tausczik, Y. R., \& Pennebaker, J. W. (2010). The Psychological Meaning of Words: LIWC and Computerized Text Analysis Methods. Journal of Language and Social Psychology, 29(1), 24-54.

Thomas, E. L. (2016). Constrained by emotion: Women, leadership, and expressing emotion in the workplace. In Handbook on Well-Being of Working Women.

Timberg, C., Shaban, H., \& Dwoskin, E. (2017). Fiery exchanges on Capitol Hill as lawmakers scold Facebook, Google and Twitter. Retrieved January 30, 2018, from https://www.washingtonpost.com/news/the-switch/wp/2017/11/01/fiery-exchangeson-capitol-hill-as-lawmakers-scold-facebook-google-and- 
twitter/?utm_term=.be887aac25ad

Tomkins, S. S. (1995). Ideology and affect. In E. V. Demos (Ed.), Exploring affect: The selected writings of Silvan S. Tomkins (pp. 109-167). New York: Cambridge Press.

Tumasjan, a., Sprenger, T. O., Sandner, P. G., \& Welpe, I. M. (2011). Election

Forecasts With Twitter: How 140 Characters Reflect the Political Landscape. Social Science Computer Review.

Valentino, N. A., Hutchings, V. L., Banks, A. J., \& Davis, A. K. (2008). Is a worried citizen a good citizen? Emotions, political information seeking, and learning via the Internet. Political Psychology, 29(2), 247-273.

Valenzuela, S., Piña, M., \& Ramírez, J. (2017). Behavioral Effects of Framing on Social Media Users: How Conflict, Economic, Human Interest, and Morality Frames Drive News Sharing. Journal of Communication.

Van Bavel, J. J., Mende-Siedlecki, P., Brady, W. J., \& Reinero, D. A. (2016). Contextual sensitivity in scientific reproducibility. Proceedings of the National Academy of Sciences, 113(23), 6454-6459.

Van Der Linden, S. (2017). The nature of viral altruism and how to make it stick. Nature Human Behaviour.

Vosoughi, S., Roy, D., \& Aral, S. (2018). The spread of true and false news online.

Science, 359(6380), 1146-1151. 
Supporting Information for:

An ideological asymmetry in the diffusion of moralized content on social media among political leaders

W. J. Brady, J. A. Wills, D. Burkart, J. T. Jost \& J. J. Van Bavel

correspondence to: jay.vanbavel@nyu.edu

\section{This file includes:}

Section 1: Exploring discrete emotions

Section 2: Exploring partisan extremity

Section 3: Accounting for frequency of language use in Trump / Clinton data

Tables S1-S24 


\section{Section 1: Exploring discrete emotions}

Clinton / Trump data. To explore which discrete emotion expressions may have been most responsible for the moral contagion effect, we further classified each moralemotional word as fitting under one or multiple emotion categories (see Methods). We focused on anger and disgust due to their distinct functions in communicating morality (Giner-Sorolla \& Espinosa, 2010), and we also included the low-arousal emotion sadness, as well as the positively-valenced emotion joy to explore potential differences in valence and arousal (Russell \& Barrett, 1999). When these discrete emotions were entered as competing predictors interacting with a Trump/Clinton indicator variable, we found that President Trump exhibited significantly greater diffusion than Clinton when using anger-related moral-emotional language $(\exp (b)=1.36, P<.001,95 \% \mathrm{Cl}=[1.36$, 2.08]). However, Clinton exhibited marginally greater diffusion than President Trump when using disgust-related moral-emotional language $(\exp (b)=0.74, P=.057,95 \% \mathrm{Cl}$ $=[0.54,1.01] ;$ see SI Appendix, Tables S4-5 for model details).

Senator data. We also explored conservative vs. liberal asymmetries, and found that conservatives' use of joy-related moral emotion expression (e.g., "faith", "respect", "hero") increased diffusion significantly more than liberals' use $(\exp (b)=1.20, P=.002$, $95 \% \mathrm{Cl}=[1.07,1.35]$ ), echoing the valence findings (these words appeared to be referencing religion or patriotism; for a list of the most viral joy-related moral emotion words for conservatives, see SI Appendix, Table S12). Interestingly, anger-related moral-emotional language $(\exp (b)=1.15, P<.001,95 \% \mathrm{Cl}=[1.08,1.23])$ and disgustrelated moral-emotional language $(\exp (b)=1.10, P=.025,95 \% \mathrm{Cl}=[1.01,1.19])$ were 
significantly associated with increased diffusion for both conservatives and liberals; see SI Appendix, Tables S13-14 for model details).

All Congress data. Replicating Study 2, we found that conservatives' use of joyrelated moral emotion expression related to religion and patriotism increased diffusion significantly more than liberals' use, $\exp (b)=1.10, P<.001,95 \% \mathrm{Cl}=[1.05,1.16])$. Regarding effects of discrete moral emotion for both parties, we replicated Study 2 in finding that anger-related moral emotion $(\exp (b)=1.14, P<.001,95 \% \mathrm{Cl}=[1.11,1.18])$ was significantly associated with increased diffusion for both conservatives and liberals. Unique to Study 2, we found that moral emotion expression related to sadness was also significantly associated with diffusion for both parties $(\exp (b)=1.10, P<.001,95 \% \mathrm{Cl}=$ [1.04, 1.16]; see SI Appendix, Tables S20-21 for model details).

\section{Section 2: Exploring Partisan extremity}

One alternative explanation for the conservative-liberal asymmetry in moral contagion found in Studies 2 and 3 is that extremity of ideology drives the asymmetry rather than ideological differences per se. In order to test this possibility, we calculated an extremity score for each Senator based on a scaled absolute value of their DWNOMINATE score. To do so, we first took the absolute value of the DW-NOMINATE scores. However, since conservatives had a greater range of extremity (conservative max extremity score $=.919$ [Mike Lee], liberal max extremity score $=.744$ [Elizabeth Warren]), we re-scaled the extremity variable for conservative senators using a $\min / \mathrm{max}$ rescaling method ${ }^{1}$. The rescaled extremity score for conservatives was then .74 . See

\footnotetext{
${ }^{1}$ For conservative seantors: abs(dw_nominate) $*$ abs(min(dw_nominate) / max (dw_nominate)
} 
Figure S1 for a comparison of frequency distributions for extremity vs. rescaled extremity variables.
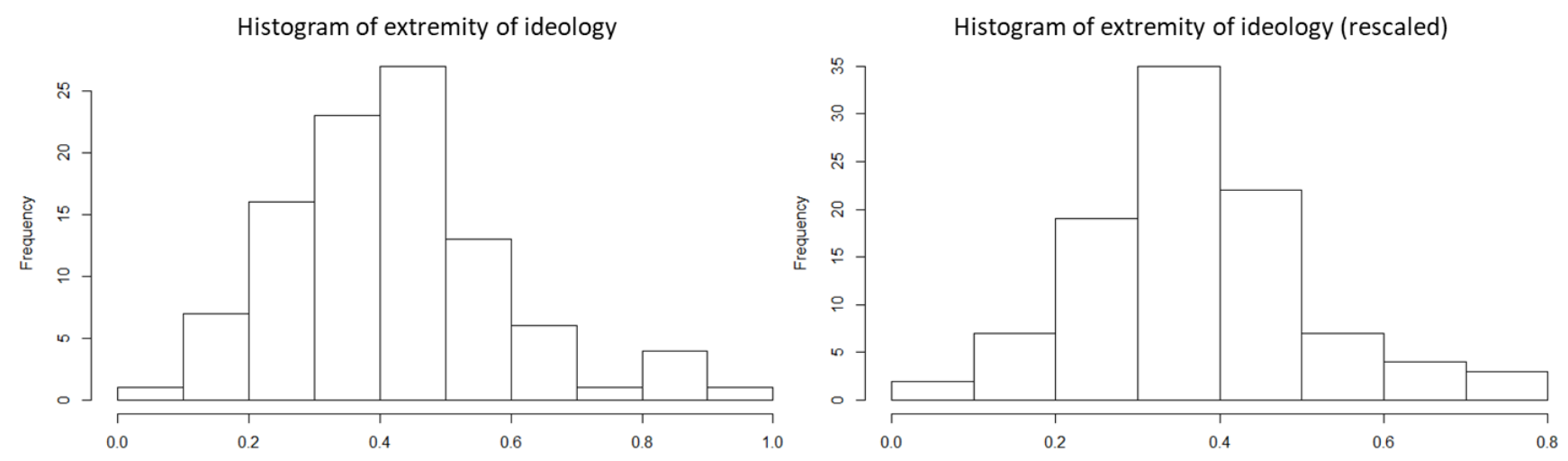

Figure S1. Frequency distributions for extremity of ideology and rescaled extremity of ideology variables.

In Study 2, we found that when adjusting for the interaction of political extremity and moral-emotional language, the conservative-liberal asymmetry in the moral contagion effect remained marginally significant $(\exp (b)=1.09, P=.056,95 \% \mathrm{Cl}=$ $[1.00,1.20])$. In fact, the interaction of extremity and moral-emotional language on diffusion was also significant $(\exp (b)=1.73, P<.001,95 \% \mathrm{Cl}=[1.31,2.29])$, suggesting that extreme liberal and conservative Senators were associated with a stronger moral contagion effect, even though on average conservative Senators were still associated with a stronger moral contagion effect (see SI Appendix, Table S22 for model details). However, again it is important to note that these effects were exaggerated by the presence of extreme outlier in Cory Booker (an extreme liberal Senator). When Cory Booker, Jeff Sessions and Thom Tillis ( $>3$ SD outliers for moral contagion estimates) were removed from the dataset, the conservative-liberal asymmetry in moral contagion was larger and significant even when adjusting for extremity of ideology, $(\exp (b)=1.14$, 
$P<.001,95 \% \mathrm{Cl}=[1.07,1.21])$, while the effect of extremity on moral contagion was also significant $(\exp (b)=1.41, P<.001,95 \% \mathrm{Cl}=[1.29,1.72])$; see SI Appendix, Table S23 for model details. Overall, these results suggest that in the Senate both conservative ideology and greater extremity were independently associated with relatively greater retweets when using moral-emotional language.

In Study 3, we found that when adjusting for the interaction of political extremity and moral-emotional language, the conservative-liberal asymmetry in the moral contagion effect remained significant $(\exp (b)=1.06, P=.012,95 \% \mathrm{Cl}=[1.01,1.10])$, and the moderating effect of political extremity on moral contagion was also significant $(\exp (b)=1.37, P=.001,95 \% \mathrm{Cl}=[1.14,1.64] ;$ see Table S24 for model details $)$. In both the Senate and the House data, the conservative-liberal asymmetry in moral contagion held over and above any effect of political extremity, although more extreme elites also exhibited a great moral contagion effect than less extreme elites.

\section{Section 3: Accounting for language frequency use in Trump / Clinton data}

Clinton's use of moral-emotional language was not associated with significant increases in retweet count, even though she used more moral-emotional language than Trump. Even though Clinton's mean amount of moral-emotional language use per tweet (0.24 words) was not much larger than Trumps ( 0.19 words), it is possible that using it more created an "over-saturation" that could explain why moral-emotional language did not appear to be as effective for her. To test this possibility, we re-ran our model adjusting for the frequency of each language category use, but found that the Clinton- 
Trump asymmetry in moral contagion was not changed by adjusting for the frequencies, $(\exp (b)=1.22, P<.001,95 \% \mathrm{Cl}=[1.14,1.32]$. 
Table S1. Retweet count as a function of language type for Hillary Clinton and President Trump in the year leading up to the 2016 Presidential election. Coefficients refer to incident rate ratios; parenthesis refer to standard errors.

\begin{tabular}{lcc}
\hline \hline & \multicolumn{2}{c}{ Retweet Count } \\
\cline { 2 - 3 } & Clinton & Trump \\
\hline Distinctly moral language & 1.01 & $1.12^{\star}$ \\
& $(0.02)$ & $(0.02)$ \\
Distinctly emotional language & $1.05^{*}$ & $0.97^{\star}$ \\
& $(0.02)$ & $(0.01)$ \\
Moral-emotional language & 1.02 & $1.25^{\star}$ \\
& $(0.03)$ & $(0.03)$ \\
Constant & $1303.49^{*}$ & $3290.85^{*}$ \\
& $(0.02)$ & $(0.02)$ \\
\hline & & 4,795 \\
\hline${ }^{\dagger} p<.10 ;{ }^{*} p<.05$ & 4,710 & \\
\hline
\end{tabular}


Table S2. Retweet count as a function of language type and effects coded candidate variable (reference group $=$ Clinton) in the year leading up to the 2016 Presidential election. Coefficients refer to incident rate ratios; parenthesis refer to standard errors.

\begin{tabular}{lc}
\hline \hline Distinctly moral language & 1.01 \\
& $(0.02)$ \\
Distinctly emotional language & $1.05^{*}$ \\
& $(0.02)$ \\
Moral-emotional language & 1.02 \\
& $(0.03)$ \\
Candidate & $2.56^{*}$ \\
& $(0.02)$ \\
Candidate * Distinctly moral language & $1.11^{*}$ \\
& $(0.03)$ \\
Candidate * Distinctly emotional language & $0.93^{*}$ \\
& $(0.02)$ \\
Candidate * Moral-emotional language & $1.23^{*}$ \\
& $(0.04)$ \\
Constant & $1379.26^{*}$ \\
\hline \hline & $(0.01)$ \\
\hline
\end{tabular}


Table S3. Retweet count as a function of language type (both positive and negative emotional language) and effects coded candidate variable (reference group = Clinton) in the year leading up to the 2016 Presidential election. Coefficients refer to incident rate ratios; parenthesis refer to standard errors.

\begin{tabular}{|c|c|}
\hline Distinctly moral language & $\begin{array}{l}1.01 \\
(0.02)\end{array}$ \\
\hline Distinctly emotional language, positive & $\begin{array}{c}1.01 \\
(0.02)\end{array}$ \\
\hline Distinctly emotional language, negative & $\begin{array}{l}1.19^{*} \\
(0.03)\end{array}$ \\
\hline Moral-emotional language, positive & $\begin{array}{c}0.96 \\
(0.04)\end{array}$ \\
\hline Moral-emotional language, negative & $\begin{array}{c}0.98 \\
(0.04)\end{array}$ \\
\hline Candidate & $\begin{array}{l}2.68^{*} \\
(0.02)\end{array}$ \\
\hline Distinctly moral language * candidate & $\begin{array}{l}1.11^{*} \\
(0.03)\end{array}$ \\
\hline Distinctly emotional language, positive * candidate & $\begin{array}{l}0.93^{*} \\
(0.02)\end{array}$ \\
\hline Distinctly emotional language, negative * candidate & $\begin{array}{l}0.92^{*} \\
(0.04)\end{array}$ \\
\hline Moral-emotional language, positive ${ }^{*}$ candidate & $\begin{array}{l}1.16^{*} \\
(0.06)\end{array}$ \\
\hline Moral-emotional language, negative ${ }^{*}$ candidate & $\begin{array}{l}1.24^{*} \\
(0.07)\end{array}$ \\
\hline Constant & $\begin{array}{c}1322.26^{*} \\
(0.02)\end{array}$ \\
\hline Observations (original messages) & 9,505 \\
\hline
\end{tabular}


Table S4. Retweet count as a function of discrete moral emotion language and effects coded candidate variable (reference group $=$ Clinton) in the year leading up to the 2016 Presidential election. Coefficients refer to incident rate ratios; parenthesis refer to standard errors.

\begin{tabular}{|c|c|}
\hline Anger-related moral-emotional language & $\begin{array}{c}0.97 \\
(0.06)\end{array}$ \\
\hline Disgust-related moral-emotional language & $\begin{array}{c}1.22^{\dagger} \\
(0.12)\end{array}$ \\
\hline Sadness-related moral-emotional language & $\begin{array}{l}1.09 \\
(0.11)\end{array}$ \\
\hline Joy-related moral-emotional language & $\begin{array}{c}1.05 \\
(0.06)\end{array}$ \\
\hline Candidate & $\begin{array}{l}2.53^{*} \\
(0.02)\end{array}$ \\
\hline Anger-related moral-emotional language * candidate & $\begin{array}{l}1.68^{*} \\
(0.11)\end{array}$ \\
\hline Disgust-related moral-emotional language * candidate & $\begin{array}{l}0.74^{\dagger} \\
(0.16)\end{array}$ \\
\hline Sadness-related moral-emotional language * candidate & $\begin{array}{c}0.82 \\
(0.16)\end{array}$ \\
\hline Joy-related moral-emotional language * candidate & $\begin{array}{c}0.94 \\
(0.09)\end{array}$ \\
\hline Constant & $\begin{array}{c}1369.09^{*} \\
(0.01)\end{array}$ \\
\hline Observations (original messages) & 9,505 \\
\hline
\end{tabular}


Table S5. Pearson correlation coefficients for discrete moral emotion language categories across Trump and Clinton data sets.

\begin{tabular}{|c|c|c|c|c|}
\hline & Anger & Disgust & Sadness & Joy \\
\hline Anger & 1.000 & $.734^{*}$ & $.747^{\star}$ & $.029^{*}$ \\
\hline Disgust & $.734^{*}$ & 1.000 & $.825^{\star}$ & $.034^{*}$ \\
\hline Sadness & $.747^{\star}$ & $.825^{\star}$ & 1.000 & $.040^{*}$ \\
\hline Joy & $.029^{*}$ & $.034^{*}$ & $.040^{*}$ & 1.000 \\
\hline $\begin{array}{l}\text { Observations } \\
\text { (original } \\
\text { messages) }\end{array}$ & 9,505 & & & \\
\hline
\end{tabular}


Table S6. Retweet count as a function of language type and covariates for U.S. Senators in the year leading up to the 2016 Presidential election. Coefficients refer to incident rate ratios; parenthesis refer to standard errors.

\begin{tabular}{lc}
\hline \hline Distinctly moral language & $1.13^{*}$ \\
& $(0.02)$ \\
Distinctly emotional language & 0.97 \\
& $(0.03)$ \\
Moral-emotional language & $1.13^{*}$ \\
& $(0.02)$ \\
Followers & $1.00^{*}$ \\
& $(0.00)$ \\
URL & $1.00^{*}$ \\
& $(0.05)$ \\
Media & $0.88^{*}$ \\
& $(0.05)$ \\
Constant & $14.20^{*}$ \\
\hline \multirow{2}{*}{ Observations (original messages) } & $(0.13)$ \\
\hline \hline${ }^{p} p<.10 ;{ }^{*} p<.05$ & 99,750 \\
\hline
\end{tabular}


Table S7. Retweet count as a function of language categories, ideology estimate (DW-NOMINATE score) and covariates for Senators in the year leading up to the 2016 Presidential election. Coefficients refer to incident rate ratios; parenthesis refer to standard errors.

\begin{tabular}{|c|c|}
\hline Distinctly moral language & $\begin{array}{l}1.13^{*} \\
(0.02)\end{array}$ \\
\hline Distinctly emotional language & $\begin{array}{c}0.97 \\
(0.02)\end{array}$ \\
\hline Moral-emotional language & $\begin{array}{c}1.13^{*} \\
(0.02)\end{array}$ \\
\hline Ideology & $\begin{array}{c}0.78 \\
(0.24)\end{array}$ \\
\hline Distinctly moral language * ideology & $\begin{array}{c}0.99 \\
(0.05)\end{array}$ \\
\hline Distinctly emotional language * ideology & $\begin{array}{c}1.13^{\dagger} \\
(0.07)\end{array}$ \\
\hline Moral-emotional language * ideology & $\begin{array}{l}1.12^{*} \\
(0.06)\end{array}$ \\
\hline Followers & $\begin{array}{l}1.00^{*} \\
(0.00)\end{array}$ \\
\hline URL & $\begin{array}{c}1.00 \\
(0.05)\end{array}$ \\
\hline Media & $\begin{array}{c}0.79^{*} \\
(0.05)\end{array}$ \\
\hline Constant & $\begin{array}{l}14.30^{*} \\
(0.14)\end{array}$ \\
\hline Observations (original messages) & 99,750 \\
\hline
\end{tabular}


Table S8. Retweet count as a function of language categories, ideology estimate (DW-NOMINATE score), and covariates for Senators in the year leading up to the 2016 Presidential election with outlier moral contagion estimates $(N=3)$ removed. Coefficients refer to incident rate ratios; parenthesis refer to standard errors.

Distinctly moral language

Distinctly emotional language

Moral-emotional language

Ideology

Distinctly moral language * ideology

Distinctly emotional language * ideology

Moral-emotional language * ideology

Followers

URL

Media

Constant

Observations (original messages)
$1.12^{*}$

(0.01)

1.00

$1.12^{*}$

$0.64^{*}$

$(0.20)$

1.04

(0.04)

1.04

(0.03)

$1.17^{*}$

$(0.04)$

1.00 *

1.03

$0.81^{*}$

$12.42^{*}$

$(0.12)$

99,750

$\overline{{ }^{\dagger} p<.10 ;{ }^{*} p<.05}$ 
Table S9. Retweet count as a function of language categories, ideology estimate (DW-NOMINATE score) gender, and covariates for Senators in the year leading up to the 2016 Presidential election. For gender, males are the reference category. Coefficients refer to incident rate ratios; parenthesis refer to standard errors.

\begin{tabular}{|c|c|}
\hline Distinctly moral language & $\begin{array}{c}1.15^{\star} \\
(0.02)\end{array}$ \\
\hline Distinctly emotional language & $\begin{array}{c}0.96 \\
(0.03)\end{array}$ \\
\hline Moral-emotional language & $\begin{array}{l}1.15^{*} \\
(0.03)\end{array}$ \\
\hline Ideology & $\begin{array}{c}0.84 \\
(0.25)\end{array}$ \\
\hline Gender & $\begin{array}{c}1.24 \\
(0.21)\end{array}$ \\
\hline Distinctly moral language * ideology & $\begin{array}{c}0.97 \\
(0.06)\end{array}$ \\
\hline Distinctly emotional language * ideology & $\begin{array}{c}1.15^{*} \\
(0.07)\end{array}$ \\
\hline Moral-emotional language * ideology & $\begin{array}{c}1.10 \\
(0.06)\end{array}$ \\
\hline Distinctly moral language * gender & $\begin{array}{c}0.94 \\
(0.04)\end{array}$ \\
\hline Distinctly emotional language * gender & $\begin{array}{c}1.04 \\
(0.03)\end{array}$ \\
\hline Moral-emotional language * gender & $\begin{array}{c}0.93^{\dagger} \\
(0.04)\end{array}$ \\
\hline Followers & $\begin{array}{l}1.00^{*} \\
(0.00)\end{array}$ \\
\hline URL & $\begin{array}{c}1.00 \\
(0.05)\end{array}$ \\
\hline Media & $\begin{array}{c}0.79^{*} \\
(0.05)\end{array}$ \\
\hline Constant & $\begin{array}{l}13.67^{\star} \\
(0.14)\end{array}$ \\
\hline
\end{tabular}


${ }^{\dagger} p<.10 ;{ }^{*} p<.05$ 
Table S10. Retweet count as a function of language categories, ideology estimate (DW-NOMINATE score) gender, and covariates for Senators in the year leading up to the 2016 Presidential election with outlier moral contagion estimates $(\mathrm{N}=3)$ removed. For gender, males are the reference category. Coefficients refer to incident rate ratios; parenthesis refer to standard errors.

\begin{tabular}{|c|c|}
\hline Distinctly moral language & $\begin{array}{c}1.12^{*} \\
(0.01)\end{array}$ \\
\hline Distinctly emotional language & $\begin{array}{c}0.99 \\
(0.01)\end{array}$ \\
\hline Moral-emotional language & $\begin{array}{l}1.13^{*} \\
(0.02)\end{array}$ \\
\hline Ideology & $\begin{array}{c}0.67^{\dagger} \\
(0.21)\end{array}$ \\
\hline Gender & $\begin{array}{c}1.17 \\
(0.18)\end{array}$ \\
\hline Distinctly moral language * ideology & $\begin{array}{c}1.03 \\
(0.03)\end{array}$ \\
\hline Distinctly emotional language * ideology & $\begin{array}{c}1.05 \\
(0.03)\end{array}$ \\
\hline Moral-emotional language * ideology & $\begin{array}{l}1.16^{*} \\
(0.04)\end{array}$ \\
\hline Distinctly moral language * gender & $\begin{array}{c}0.98 \\
(0.02)\end{array}$ \\
\hline Distinctly emotional language * gender & $\begin{array}{c}1.01 \\
(0.02)\end{array}$ \\
\hline Moral-emotional language * gender & $\begin{array}{c}0.96 \\
(0.03)\end{array}$ \\
\hline Followers & $\begin{array}{l}1.00^{*} \\
(0.00)\end{array}$ \\
\hline URL & $\begin{array}{c}1.03 \\
(0.05)\end{array}$ \\
\hline Media & $\begin{array}{l}0.81^{*} \\
(0.05)\end{array}$ \\
\hline Constant & $\begin{array}{l}12.01^{*} \\
(0.13)\end{array}$ \\
\hline
\end{tabular}


${ }^{\dagger} p<.10 ;{ }^{*} p<.05$ 
Table S11. Retweet count as a function of language type (both positive and negative emotional language) and ideology estimate (DW-NOMINATE score) for Senators in the year leading up to the 2016 Presidential election. Coefficients refer to incident rate ratios; parenthesis refer to standard errors.

\begin{tabular}{lc} 
Distinctly moral language & $1.13^{\star}$ \\
& $(0.02)$ \\
Distinctly emotional language, positive & $0.93^{*}$ \\
& $(0.02)$ \\
Distinctly emotional language, negative & $1.22^{*}$ \\
& $(0.02)$ \\
Moral-emotional language, positive & 1.02 \\
& $(0.02)$ \\
Moral-emotional language, negative & $1.24^{\star}$ \\
& $(0.04)$ \\
Ideology & 0.78 \\
Distinctly moral language * ideology & $(0.24)$ \\
& 0.99 \\
Distinctly emotional language, positive * ideology & $(0.05)$ \\
Distinctly emotional language, negative * ideology & $1.14 \dagger$ \\
Moral-emotional language, positive * ideology & $(0.08)$ \\
& $1.10^{\star}$ \\
& $(0.05)$ \\
& $1.14^{\star}$ \\
& $(0.05)$ \\
& 1.02 \\
& $(0.09)$ \\
& $14.53^{*}$ \\
& $(0.14)$ \\
\hline
\end{tabular}

${ }^{+} p<.10 ;{ }^{*} p<.05$ 
Table S12. Top 5 "joy"-related moral-emotional words associated with the most viral tweets for conservative Senators, among words appearing at least 10 times in conservative Senators' tweets.

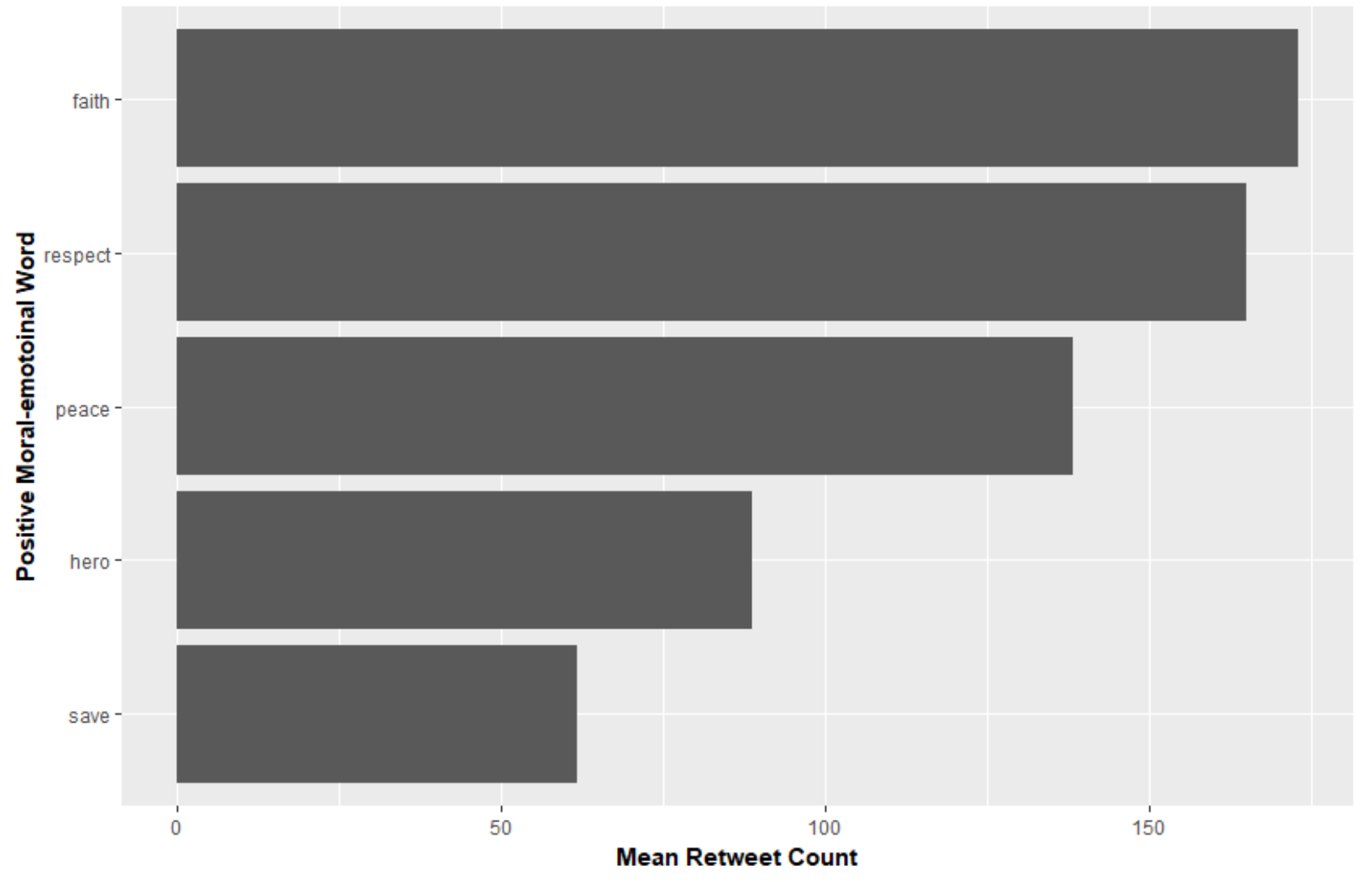


Table S13. Retweet count as a function of discrete moral emotion language and ideology estimate (DWNOMINATE score) for Senators in the year leading up to the 2016 Presidential election. Coefficients refer to incident rate ratios; parenthesis refer to standard errors.

\begin{tabular}{|c|c|}
\hline Anger-related language & $\begin{array}{l}1.15^{*} \\
(0.03)\end{array}$ \\
\hline Disgust-related language & $\begin{array}{l}1.10^{*} \\
(0.04)\end{array}$ \\
\hline Sadness-related language & $\begin{array}{c}1.08^{\dagger} \\
(0.04)\end{array}$ \\
\hline Joy-related language & $\begin{array}{c}1.02 \\
(0.03)\end{array}$ \\
\hline Ideology & $\begin{array}{c}0.76 \\
(0.23)\end{array}$ \\
\hline Anger-related language * ideology & $\begin{array}{c}1.10 \\
(0.07)\end{array}$ \\
\hline Disgust-related language * ideology & $\begin{array}{c}0.93 \\
(0.09)\end{array}$ \\
\hline Sadness-related language * ideology & $\begin{array}{c}1.11 \\
(0.11)\end{array}$ \\
\hline Joy-related language * ideology & $\begin{array}{l}1.20^{*} \\
(0.06)\end{array}$ \\
\hline Followers & $\begin{array}{l}1.00^{*} \\
(0.00)\end{array}$ \\
\hline URL & $\begin{array}{c}1.05 \\
(0.06)\end{array}$ \\
\hline Media & $\begin{array}{l}0.78^{*} \\
(0.08)\end{array}$ \\
\hline Constant & $\begin{array}{l}7.38^{*} \\
(0.12)\end{array}$ \\
\hline Observations (original messages) & 99,750 \\
\hline
\end{tabular}

${ }^{\dagger} p<.10 ;{ }^{*} p<.05$ 
Table S14. Pearson correlation coefficients for discrete moral emotion language categories across Senator data set.

\begin{tabular}{lcccc}
\hline \hline & Anger & Disgust & Sadness & Joy \\
\hline Anger & 1.000 & $.629^{*}$ & $.616^{*}$ & $-.008^{*}$ \\
Disgust & $.629^{*}$ & 1.000 & $.818^{*}$ & -.000 \\
Sadness & $.616^{*}$ & $.818^{*}$ & 1.000 & .001 \\
Joy & $-.008^{*}$ & -.000 & .001 & 1.000 \\
\hline $\begin{array}{l}\text { Observations (original } \\
\text { messages) }\end{array}$ & 99,750 & & & \\
\hline \hline${ }^{\dagger} p<.10 ;{ }^{*} p<.05$ & & & & \\
\end{tabular}


Table S15. Retweet count as a function of language type and covariates for all U.S. Congress members in the year leading up to the 2016 Presidential election. Coefficients refer to incident rate ratios; parenthesis refer to standard errors.

\begin{tabular}{lc}
\hline \hline Distinctly moral language & $1.13^{*}$ \\
& $(0.01)$ \\
Distinctly emotional language & 0.98 \\
& $(0.01)$ \\
Moral-emotional language & $1.12^{*}$ \\
& $(0.01)$ \\
Followers & $1.00^{*}$ \\
& $(0.00)$ \\
Media & $0.80^{*}$ \\
& $(0.02)$ \\
Constant & $6.64^{*}$ \\
\hline \multirow{2}{*}{ Observations (original messages) } & $(0.06)$ \\
\hline \hline
\end{tabular}

$\overline{{ }^{\dagger} p<.10 ;{ }^{*} p<.05}$ 
Table S16. Retweet count as a function of language categories, ideology estimate (DW-NOMINATE score) and covariates for all U.S. Congress members in the year leading up to the 2016 Presidential election. Coefficients refer to incident rate ratios; parenthesis refer to standard errors.

\begin{tabular}{|c|c|}
\hline Distinctly moral language & $\begin{array}{l}1.12^{*} \\
(0.01)\end{array}$ \\
\hline Distinctly emotional language & $\begin{array}{c}0.98 \\
(0.00)\end{array}$ \\
\hline Moral-emotional language & $\begin{array}{l}1.12^{*} \\
(0.01)\end{array}$ \\
\hline Ideology & $\begin{array}{l}0.88^{*} \\
(0.05)\end{array}$ \\
\hline Distinctly moral language * ideology & $\begin{array}{c}1.01 \\
(0.02)\end{array}$ \\
\hline Distinctly emotional language * ideology & $\begin{array}{l}1.07^{*} \\
(0.03)\end{array}$ \\
\hline Moral-emotional language * ideology & $\begin{array}{l}1.07^{*} \\
(0.03)\end{array}$ \\
\hline Followers & $\begin{array}{l}1.00^{*} \\
(0.00)\end{array}$ \\
\hline Media & $\begin{array}{l}0.80^{*} \\
(0.02)\end{array}$ \\
\hline Constant & $\begin{array}{l}6.62^{*} \\
(0.06)\end{array}$ \\
\hline Observations (original messages) & 276,750 \\
\hline
\end{tabular}


Table S17. Retweet count as a function of language categories, ideology estimate (DW-NOMINATE score) gender, and covariates for U.S. Congress in the year leading up to the 2016 Presidential election. For gender, males are the reference category. Coefficients refer to incident rate ratios; parenthesis refer to standard errors.

\begin{tabular}{|c|c|}
\hline Distinctly moral language & $\begin{array}{l}1.11^{*} \\
(0.01)\end{array}$ \\
\hline Distinctly emotional language & $\begin{array}{c}1.00 \\
(0.01)\end{array}$ \\
\hline Moral-emotional language & $\begin{array}{l}1.13^{*} \\
(0.02)\end{array}$ \\
\hline Ideology & $\begin{array}{l}0.88^{*} \\
(0.05)\end{array}$ \\
\hline Gender & $\begin{array}{l}0.85^{\star} \\
(0.08)\end{array}$ \\
\hline Distinctly moral language * ideology & $\begin{array}{c}1.00 \\
(0.00)\end{array}$ \\
\hline Distinctly emotional language * ideology & $\begin{array}{c}1.08^{*} \\
(0.04)\end{array}$ \\
\hline Moral-emotional language * ideology & $\begin{array}{l}1.07^{*} \\
(0.03)\end{array}$ \\
\hline Distinctly moral language * gender & $\begin{array}{c}1.01 \\
(0.02)\end{array}$ \\
\hline Distinctly emotional language * gender & $\begin{array}{c}0.97 \\
(0.02)\end{array}$ \\
\hline Moral-emotional language ${ }^{*}$ gender & $\begin{array}{c}1.00 \\
(0.02)\end{array}$ \\
\hline Followers & $\begin{array}{l}1.00^{*} \\
(0.00)\end{array}$ \\
\hline Media & $\begin{array}{l}0.80^{*} \\
(0.02)\end{array}$ \\
\hline Constant & $\begin{array}{l}7.56^{*} \\
(0.06)\end{array}$ \\
\hline Observations (original messages) & 276,750 \\
\hline
\end{tabular}

$\overline{{ }^{\dagger} p<.10 ;{ }^{*} p<.05}$ 
Table S18. Retweet count as a function of language categories, ideology estimate (DW-NOMINATE score) gender, age, race and covariates for U.S. Congress in the year leading up to the 2016 Presidential election. For gender, males are the reference category. Age is scaled in terms of 10 -year units. Race is a binary white / non-white variable where white is the reference category. Coefficients refer to incident rate ratios; parenthesis refer to standard errors.

Distinctly moral language

Distinctly emotional language

Moral-emotional language

Ideology

Gender

Age

0.72

Race

Distinctly moral language * ideology

Distinctly emotional language * ideology

Moral-emotional language * ideology

Distinctly moral language * gender

Distinctly emotional language * gender $\quad 0.97$

Moral-emotional language * gender

Distinctly moral language * age 


$\begin{array}{lc}\text { Moral-emotional language *age } & 0.96^{*} \\ & (0.01) \\ \text { Distinctly moral language * race } & 0.94^{*} \\ & (0.03) \\ \text { Distinctly emotional language * race } & 1.04 \\ & (0.02) \\ \text { Moral-emotional language * race } & 0.93^{*} \\ \text { Followers } & (0.03) \\ & 1.00^{\star} \\ \text { Media } & (0.00) \\ & 0.80^{*} \\ \text { Constant } & (0.02) \\ & 8.89^{*} \\ \end{array}$

Observations (original messages) $\quad 276,750$

$\overline{{ }^{\dagger} p<.10 ;{ }^{*} p<.05}$ 
Table S19. Retweet count as a function of language type (both positive and negative emotional language) and ideology estimate (DW-NOMINATE score) for all Congress members in the year leading up to the 2016 Presidential election. Coefficients refer to incident rate ratios; parenthesis refer to standard errors.

\begin{tabular}{|c|c|}
\hline Distinctly moral language & $\begin{array}{c}1.12^{*} \\
(0.01)\end{array}$ \\
\hline Distinctly emotional language, positive & $\begin{array}{l}0.95^{\star} \\
(0.01)\end{array}$ \\
\hline Distinctly emotional language, negative & $\begin{array}{l}1.21^{*} \\
(0.01)\end{array}$ \\
\hline Moral-emotional language, positive & $\begin{array}{l}1.02^{*} \\
(0.01)\end{array}$ \\
\hline Moral-emotional language, negative & $\begin{array}{l}1.26^{*} \\
(0.02)\end{array}$ \\
\hline Ideology & $\begin{array}{l}0.83^{*} \\
(0.06)\end{array}$ \\
\hline Distinctly moral language * ideology & $\begin{array}{c}1.01 \\
(0.02)\end{array}$ \\
\hline Distinctly emotional language, positive * ideology & $\begin{array}{l}1.07^{*} \\
(0.04)\end{array}$ \\
\hline Distinctly emotional language, negative * ideology & $\begin{array}{c}1.06^{\star} \\
(0.02)\end{array}$ \\
\hline Moral-emotional language, positive * ideology & $\begin{array}{l}1.10^{*} \\
(0.02)\end{array}$ \\
\hline Moral-emotional language, negative * ideology & $\begin{array}{c}0.98 \\
(0.04)\end{array}$ \\
\hline Media & $\begin{array}{l}0.78^{*} \\
(0.02)\end{array}$ \\
\hline Followers & $\begin{array}{l}1.00^{*} \\
(0.00)\end{array}$ \\
\hline Constant & $\begin{array}{l}6.73^{*} \\
(0.05)\end{array}$ \\
\hline Observations (original messages) & 276,750 \\
\hline
\end{tabular}

$\overline{{ }^{\dagger} p<.10 ;{ }^{*} p<.05}$ 
Table S20. Retweet count as a function of discrete moral emotion language and ideology estimate (DWNOMINATE score) for all of Congress in the year leading up to the 2016 Presidential election.

Coefficients refer to incident rate ratios; parenthesis refer to standard errors.

\begin{tabular}{|c|c|}
\hline Anger-related language & $\begin{array}{l}1.14^{*} \\
(0.02)\end{array}$ \\
\hline Disgust-related language & $\begin{array}{c}1.03 \\
(0.03)\end{array}$ \\
\hline Sadness-related language & $\begin{array}{l}1.10^{*} \\
(0.03)\end{array}$ \\
\hline Joy-related language & $\begin{array}{c}1.00 \\
(0.01)\end{array}$ \\
\hline Ideology & $\begin{array}{c}0.89^{\star} \\
(0.05)\end{array}$ \\
\hline Anger-related language * ideology & $\begin{array}{c}1.04 \\
(0.04)\end{array}$ \\
\hline Disgust-related language * ideology & $\begin{array}{c}0.99 \\
(0.07)\end{array}$ \\
\hline Sadness-related language * ideology & $\begin{array}{c}0.89^{\dagger} \\
(0.11)\end{array}$ \\
\hline Joy-related language * ideology & $\begin{array}{l}1.10^{*} \\
(0.03)\end{array}$ \\
\hline Followers & $\begin{array}{l}1.00^{*} \\
(0.00)\end{array}$ \\
\hline Media & $\begin{array}{l}0.81^{*} \\
(0.02)\end{array}$ \\
\hline Constant & $\begin{array}{l}4.56^{*} \\
(0.04)\end{array}$ \\
\hline Observations (original messages) & 276,750 \\
\hline
\end{tabular}


Table S21. Pearson correlation coefficients for discrete moral emotion language categories across all of Congress.

\begin{tabular}{lcccc}
\hline \hline & Anger & Disgust & Sadness & Joy \\
\hline Anger & 1.000 & $.647^{*}$ & $.640^{*}$ & .002 \\
Disgust & $.647^{*}$ & 1.000 & $.839^{*}$ & $.008^{*}$ \\
Sadness & $.640^{*}$ & $.839^{*}$ & 1.000 & $.007^{*}$ \\
Joy & .002 & & $.007^{*}$ & 1.000 \\
\hline $\begin{array}{l}\text { Observations (original } \\
\text { messages) }\end{array}$ & 976,750 & $008^{*}$ & & \\
\hline \hline $\begin{array}{l}{ }^{p} p<.10 ;{ }^{*} p<.05 \\
\end{array}$ & & & \\
\hline
\end{tabular}

$\overline{{ }^{\dagger} p<.10 ;{ }^{*} p<.05}$ 
Table S22. Retweet count as a function of language categories, ideology estimate (DW-NOMINATE score), extremity of ideology, and covariates for Senators in the year leading up to the 2016 Presidential election. Coefficients refer to incident rate ratios; parenthesis refer to standard errors.

\begin{tabular}{|c|c|}
\hline Distinctly moral language & $\begin{array}{l}1.13^{*} \\
(0.01)\end{array}$ \\
\hline Distinctly emotional language & $\begin{array}{c}0.98 \\
(0.01)\end{array}$ \\
\hline Moral-emotional language & $\begin{array}{l}1.14^{*} \\
(0.02)\end{array}$ \\
\hline Ideology & $\begin{array}{c}0.65^{\dagger} \\
(0.24)\end{array}$ \\
\hline Extremity of ideology (EOI) & $\begin{array}{l}8.76^{*} \\
(0.77)\end{array}$ \\
\hline Distinctly moral language * ideology & $\begin{array}{c}0.97 \\
(0.05)\end{array}$ \\
\hline Distinctly emotional language * ideology & $\begin{array}{l}1.13^{*} \\
(0.05)\end{array}$ \\
\hline Moral-emotional language * ideology & $\begin{array}{c}1.09^{\dagger} \\
(0.05)\end{array}$ \\
\hline Distinctly moral language * EOI & $\begin{array}{c}1.58^{*} \\
(0.16)\end{array}$ \\
\hline Distinctly emotional language * EOI & $\begin{array}{c}0.68^{*} \\
(0.15)\end{array}$ \\
\hline Moral-emotional language * EOI & $\begin{array}{c}1.73^{\star} \\
(0.14)\end{array}$ \\
\hline Followers & $\begin{array}{l}1.00^{*} \\
(0.00)\end{array}$ \\
\hline URL & $\begin{array}{c}1.00 \\
(0.05)\end{array}$ \\
\hline Media & $\begin{array}{l}0.79^{*} \\
(0.05)\end{array}$ \\
\hline Constant & $\begin{array}{l}14.14^{*} \\
(0.14)\end{array}$ \\
\hline Observations (original messages) & 99,750 \\
\hline
\end{tabular}


${ }^{\dagger} p<.10 ;{ }^{*} p<.05$ 
Table S23. Retweet count as a function of language categories, ideology estimate (DW-NOMINATE score), extremity of ideology, and covariates for Senators in the year leading up to the 2016 Presidential election with outlier moral contagion estimates $(N=3)$ removed. Coefficients refer to incident rate ratios; parenthesis refer to standard errors.

\begin{tabular}{|c|c|}
\hline Distinctly moral language & $\begin{array}{l}1.12^{*} \\
(0.01)\end{array}$ \\
\hline Distinctly emotional language & $\begin{array}{c}1.00 \\
(0.01)\end{array}$ \\
\hline Moral-emotional language & $\begin{array}{l}1.13^{*} \\
(0.01)\end{array}$ \\
\hline Ideology & $\begin{array}{c}0.52^{*} \\
(0.18)\end{array}$ \\
\hline Extremity of ideology (EOI) & $\begin{array}{c}12.09^{*} \\
(0.70)\end{array}$ \\
\hline Distinctly moral language * ideology & $\begin{array}{c}1.02 \\
(0.02)\end{array}$ \\
\hline Distinctly emotional language * ideology & $\begin{array}{c}1.06^{\dagger} \\
(0.03)\end{array}$ \\
\hline Moral-emotional language * ideology & $\begin{array}{c}1.14^{*} \\
(0.03)\end{array}$ \\
\hline Distinctly moral language * EOI & $\begin{array}{c}1.31^{*} \\
(0.06)\end{array}$ \\
\hline Distinctly emotional language * $\mathrm{EOI}$ & $\begin{array}{c}0.86^{\dagger} \\
(0.15)\end{array}$ \\
\hline Moral-emotional language * EOI & $\begin{array}{c}1.49^{*} \\
(0.07)\end{array}$ \\
\hline Followers & $\begin{array}{l}1.00^{*} \\
(0.00)\end{array}$ \\
\hline URL & $\begin{array}{c}1.03 \\
(0.05)\end{array}$ \\
\hline Media & $\begin{array}{l}0.81^{*} \\
(0.05)\end{array}$ \\
\hline Constant & $\begin{array}{c}12.15^{\star} \\
(0.11)\end{array}$ \\
\hline
\end{tabular}


${ }^{\dagger} p<.10 ;{ }^{*} p<.05$ 
Table S24. Retweet count as a function of language categories, ideology estimate (DW-NOMINATE score), extremity of ideology, and covariates for all Congress members in the year leading up to the 2016 Presidential election. Coefficients refer to incident rate ratios; parenthesis refer to standard errors.

\begin{tabular}{|c|c|}
\hline Distinctly moral language & $\begin{array}{l}1.12^{*} \\
(0.01)\end{array}$ \\
\hline Distinctly emotional language & $\begin{array}{c}0.99^{\dagger} \\
(0.01)\end{array}$ \\
\hline Moral-emotional language & $\begin{array}{l}1.13^{*} \\
(0.01)\end{array}$ \\
\hline Ideology & $\begin{array}{l}0.88^{*} \\
(0.06)\end{array}$ \\
\hline Extremity of ideology (EOI) & $\begin{array}{c}1.04 \\
(0.42)\end{array}$ \\
\hline Distinctly moral language * ideology & $\begin{array}{c}1.00 \\
(0.02)\end{array}$ \\
\hline Distinctly emotional language * ideology & $\begin{array}{c}1.07^{*} \\
(0.03)\end{array}$ \\
\hline Moral-emotional language * ideology & $\begin{array}{l}1.06^{*} \\
(0.02)\end{array}$ \\
\hline Distinctly moral language * EOI & $\begin{array}{l}1.29^{*} \\
(0.09)\end{array}$ \\
\hline Distinctly emotional language * EOI & $\begin{array}{l}0.77^{*} \\
(0.11)\end{array}$ \\
\hline Moral-emotional language * EOI & $\begin{array}{l}1.29^{*} \\
(0.09)\end{array}$ \\
\hline Followers & $\begin{array}{l}1.00^{*} \\
(0.00)\end{array}$ \\
\hline Media & $\begin{array}{l}0.80^{*} \\
(0.02)\end{array}$ \\
\hline Constant & $\begin{array}{l}6.62^{*} \\
(0.06)\end{array}$ \\
\hline Observations (original messages) & 276,750 \\
\hline
\end{tabular}

${ }^{+} p<.10 ;{ }^{*} p<.05$ 